\title{
Effects of a parent training using telehealth: Equity and access to early intervention for rural families
}

\author{
Deborah L. Rooks-Ellis' ${ }^{1}$, Sarah K. Howorth ${ }^{2}$, Susane Boulette³ ${ }^{3}$ Megan Kunze', \\ Ella Sulinski ${ }^{5}$
}

\begin{abstract}
Children living in geographically rural areas may have limited access to early, intensive evidence-based interventions suggesting children residing in these areas are less likely to experience positive outcomes than their urban-dwelling peers. Telehealth offers an option to rural families seeking early intervention by using communication technologies where providers are able to consult and deliver services in real-time over geographical distances. To our knowledge, no other study has examined the implementation of P-ESDM in rural natural environments within the framework of the state's early intervention program. Using a multiple baseline design across participants, the current study investigated the effects of the parent-Early Start Denver Model implemented within a rural northeastern state's existing IDEA Part C early intervention program. Parents demonstrated increased fidelity to intervention strategies and reported satisfaction with the program's ease of implementation and observed child gains. Statistically significant pre-to post- change in children's ASD symptomatology were reported for the domains of communication, social reciprocity and repetitive and restricted behaviors. Support for parent-mediated interventions, the importance of fidelity of implementation for sustainability of intervention strategies, and the need to explore telehealth as a viable service delivery option to improve developmental trajectories for toddlers with autism are discussed.
\end{abstract}

\section{Article History \\ Received: 05 May 2020 \\ Accepted: 09 July 2020}

\section{Keywords}

Early intervention; Autism; Parent training; Telehealth;

Rural; Family-practices

\section{Introduction}

Autism spectrum disorder (ASD) is an early emerging neurodevelopmental disorder defined by delays in social-communication (i.e., social-emotional reciprocity, nonverbal communication, and social relationships) and the presence of restricted and repetitive behaviors, interests, or activities, (i.e., stereotyped or repetitive motor movements, use of objects, or speech; inflexibility; restricted interests or focus; or hyper- or hypo-reactivity to sensory input) (American Psychiatric Association [APA], 2013). The prevalence of ASD has steadily risen to the current rate of 1 in 54 children in the U.S. (Maenner et al., 2020). In the past decade, the age for a reliable diagnosis of ASD has decreased to as early as 14-months with the recommended age for early diagnosis at 18-months (Hyman, Levy, \& Myers, 2020; Pierce et al., 2019). Early diagnosis has led to an increased demand for developmental and behavioral early intervention. The supply of services has not kept up with this demand, forcing families to wait for these intervention services (Hyman et al., 2020; Smith-Young, Chafe, \& Audas, 2020).

\section{Early Intervention for ASD Population}

The benefits of early intervention are long established in research (Chawarska, Macari, Volkmar, Kim, \& Shic, 2014; Estes et al., 2014; Hyman et al., 2020). Interventions initiated before age three have a greater and more positive impact on development than interventions that began after age five (Kasari,

\footnotetext{
${ }^{1}$ University of Maine, School of Learning and Teaching, Orono, ME, USA, e-mail deborah.l.rooks@maine.edu, ORCID: $\underline{\text { https://orcid.org/0000-0002-4317-1593 }}$

2 University of Maine, School of Learning and Teaching," Orono, ME, USA, e-mail: sarah.howorth@maine.edu, ORCID: https://orcid.org/0000-0002-4292-301X

${ }^{3}$ Maine Department of Education, Maine Child Development Services, Augusta, ME, USA, e-mail: sue.boulette@gmail.com, ORCID: https://orcid.org/0000-0003-4566-7995

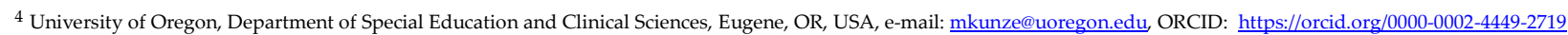

${ }^{5}$ University of Maine, School of Social Work, Orono, ME, USA, e-mail: ella.sulinski@maine.edu, ORCID: https://orcid.org/0000-0002-1830-5609
} 
Gulsrud, Freeman, Paparella, \& Hellemann, 2012; Kasari, Gulsrud, Wong, Kwon, \& Locke, 2010). Specifically, children with autism who receive early, intensive interventions demonstrate improvements in social-communication and adaptive skills with decreased engagement in restricted and repetitive behaviors; often demonstrating improvements in adaptive functioning throughout childhood and later in life (Lin \& Koegel, 2018; Reichow, Hume, Barton, \& Boyd, 2018; Shire, Gulsrud, \& Kasari, 2016). The positive outcomes associated with early intervention have been attributed to systematically implemented evidence-based interventions (Wong et al., 2015). Evaluation of intervention effectiveness as measured by fidelity (Caron, Bérubé, \& Paquet, 2017), and assessment of these interventions for usability and acceptability (e.g., measurement of social validity, generalization to other caregivers, and maintenance over time), as well as flexibility (e.g., planning for uniqueness of individualized behavior targets), continue to raise the bar; ideally resulting in established, high-quality intervention packages to better target ASD symptomatology and serve young children and families (Matson \& Goldin, 2014; Matson \& Konst, 2013; Matson \& Rieske, 2014; Rivard et al., 2017; Zwaigenbaum et al., 2015).

\section{Parent-Mediated Early Intervention}

Parent-mediated interventions are defined as "technique-focused interventions where the parent is the agent of change and the child is the direct beneficiary of treatment" (Bearss, Burrell, Stewart, \& Scahill, 2015; Bearss et al., 2018). Parent-mediated interventions can positively impact child outcomes, which speaks to the importance of individualized, evidence-based early intervention by parents as mediators and adequate interventionist coaching (Beaudoin, Sébire, \& Couture, 2019; Fettig \& Ostrosky, 2011). Recent studies have suggested that when parents are actively engaged in the treatment process and are coached to incorporate specific behavioral and developmental strategies into daily routines and family activities, then positive outcomes are achieved for young children with ASD (McIntyre \& Zemantic, 2017). Likewise, researchers have demonstrated parent involvement helps to facilitate generalization across environments, thereby providing the "real life" intensity of services necessary for significant changes in many toddlers with ASD (Brian, Smith, Zwaigenbaum, \& Bryson, 2017; McIntyre \& Zemantic, 2017; Wallace \& Rogers, 2010).

Telehealth (i.e., two-way computer-based videoconferencing) research when used with families of children with ASD is increasing. For example, functional communication training (Wacker et al., 2013, Wainer \& Ingersoll, 2015), pivotal response training (Nefdt, Koegel, Singer, \& Gerber, 2010), and behavioral consultation (Simacek, Dimian, \& McComas, 2017) have been successfully delivered using telehealth with this population. This transference of intervention skills through coaching of parents via telehealth has become more prominent (Ashburner, Vickerstaff, Beetge, \& Copley, 2016). In fact, telehealth has shown to be a successful means of training educators and caregivers in both school and early intervention settings to conduct functional assessments, create individualized behavior plans and innovative classroom management techniques (Neely, Rispoli, Gerow, \& Hong, 2016). Similarly, it has been demonstrated that fidelity of parent-mediated intervention has been at higher levels when compared to similar interventions delivered face to face (McDuffie et al., 2016). More recently, telehealth has been used to train parents of young children with autism to implement early intervention strategies in their home using the parentimplemented Early Start Denver Model (P-ESDM), which employs the science of applied behavior analysis and developmental, relationship-based intervention (Rogers, Dawson, \& Vismara, 2012; Vismara et al., 2018). Parents reported positivity toward the use of technology and telehealth as a means to learn parentled intervention skills, and findings demonstrated emerging support for P-ESDM (Rogers, et al., 2012; Vismara et al., 2018).

\section{Access for Families in Rural Areas}

Children living in geographically rural areas may have limited access to early, intensive evidencebased interventions suggesting children residing in these areas are less likely to experience positive outcomes than their urban-dwelling peers (Mello, Goldman, Urbano, \& Hodapp, 2016). Access to trained providers is also identified as a barrier for rural families as they are often made to wait their turn for services or face additional costs to travel long distances to obtain necessary services widening the equity gap due 
Effects of a parent training using telehealth: Equity and access to early intervention...

to geographical location (Martinez et al., 2018).

Telehealth offers an option to rural families seeking early intervention by using communication technologies where providers are able to consult and deliver services in real-time over geographical distances. Telehealth integrates principles of adult learning within the multimedia environment to increase parents' understanding, retention, and use of early intervention (Baggett et al., 2010). Increasing the availability of evidence-based interventions through telehealth may be a valid solution to closing the gap between service demand and availability in rural and underserved areas.

\section{Current Study}

The current study investigated the effects of the P-ESDM as implemented by an early interventionist present within the state's existing Individuals with Disabilities Education Act (IDEA, 2004) Part C early intervention program. The study examined the feasibility of parent implementation of P-ESDM via telehealth to allow for statewide implementation of P-ESDM across a rural northeastern state to improve outcomes for young children with ASD and their families. Additionally, researchers sought to understand the pre to post change in child's ASD symptomatology and the usability of the telehealth presentation for families, specifically for families residing in rural and underserved areas. To our knowledge, no other study has examined the implementation of P-ESDM in rural natural environments within the framework of the state's early intervention program. Specifically, the research questions for this study were:

Research Question 1: Is there a functional relationship between parents' fidelity of implementation of PESDM intervention strategies and their participation in P-ESDM parent training via telehealth?

Research Question 2: What changes in children's ASD symptoms do parents report? And

Research Question 3: How do parents residing in rural areas describe the usability and acceptability of PESDM via telehealth?

\section{Method}

\section{Participants and Setting}

Family participants. Family participants were recruited through the state's existing IDEA Part C early intervention program with a specific focus on recruiting families from rural and underserved areas. Families represented seven of the state's nine IDEA Part $C$ early intervention program sites. Inclusionary criteria for the parent-child dyads were as follows: (a) child was enrolled in the state's early intervention program as defined by IDEA (b) child had high risk (i.e., M-CHAT scores, sibling with ASD, informed clinical opinion) or an existing diagnosis of ASD by a licensed psychologist or physician, (c) parents provided informed consent for at least one primary parent and child to participate in study activities, (d) participating parent was able to participate in all sessions, and (e) parent had access to technology to support Zoom ${ }^{\circledR}$ video conferencing (e.g., internet, smart phone, computer, laptop, tablet).

A total of ten parent-child dyads participated in the study. Children ranged in age from 25 to 33 months at the start of the study, with a mean age of 29.3 months. None of the children were receiving services outside of the parent-implemented intervention during the course of this study. Parent participants were female $(9 / 10,90 \%)$ and male $(1 / 10,10 \%)$ and reported as Caucasian $(8 / 10,80 \%)$, Hispanic $(1 / 10,10 \%)$, and Native American $(1 / 10,10 \%)$, with $60 \%$ (6/10) having completed high school or some college, and $40 \%(4 / 10)$ having earned a college degree. Participants were employed part-to-full time (6/10, $60 \%$ ), others reported not being employed outside of the home $(3 / 6,30 \%)$, and one parent chose not to respond $(1 / 10,10 \%)$. Six parents $(60 \%)$ reported high internet usage (e.g., more than 5 hours/day) and four parents $(40 \%)$ reported low internet usage (e.g., less than 5 hours/day). Income was reported as $\$ 50,000 /$ year or higher by $60 \%(6 / 10)$ participants, with $40 \%(4 / 10)$ having earned less than $\$ 50,000 /$ year. Using the U.S. Census Bureau's measure of population size and density to define rural, $100 \%$ of participating families lived in rural settings. 
Setting. Assessment and intervention activities were conducted in family participants' homes in person during baseline, and via internet-based telehealth during intervention. Family demographic information is included in Table 1.

Table 1. Child and family characteristics

\begin{tabular}{|c|c|}
\hline Baseline characteristics & $\mathrm{N}=10$ \\
\hline Child's age at enrollment (months) & $M=29.3 \quad(\mathrm{SD}=2.36)$ \\
\hline \multicolumn{2}{|l|}{ Child's gender } \\
\hline Male & 6 \\
\hline Female & 4 \\
\hline \multicolumn{2}{|l|}{ Child's ethnicity } \\
\hline Hispanic & 1 \\
\hline American Indian or Alaska Native & 1 \\
\hline Caucasian & 8 \\
\hline \multicolumn{2}{|l|}{ Parent's gender } \\
\hline Male & 1 \\
\hline Female & 9 \\
\hline \multicolumn{2}{|l|}{ Parent's age } \\
\hline $25-34$ & 6 \\
\hline $35-44$ & 3 \\
\hline $55+$ & 1 \\
\hline \multicolumn{2}{|l|}{ Geographic setting } \\
\hline Rural & 10 \\
\hline \multicolumn{2}{|l|}{ Family income } \\
\hline Less than $\$ 50,000$ & 4 \\
\hline More than $\$ 50,000$ & 6 \\
\hline \multicolumn{2}{|l|}{ Parent's education } \\
\hline High school & 1 \\
\hline Some college & 5 \\
\hline College degree & 3 \\
\hline Graduate degree & 1 \\
\hline \multicolumn{2}{|l|}{ Parent's employment } \\
\hline Not employed outside of the home & 3 \\
\hline Part- or full-time employment & 6 \\
\hline \multicolumn{2}{|l|}{ Parent's internet use } \\
\hline Low internet use & 4 \\
\hline High internet use & 6 \\
\hline
\end{tabular}

\section{Experimental Design}

Research activities and training protocols were approved by the university's institutional review board (IRB). This study used a concurrent multiple baseline across participants design to evaluate the effects of a parent-implemented intervention for toddlers with ASD in terms of three dependent variables: (a) fidelity of parents' implementation of intervention strategies, (b) pre to post change in children's ASD symptomatology, and (c) parent description of the usability and acceptability of P-ESDM via telehealth. Each family served as its own control. To meet the quality indicators and standards of single-case experimental research, a minimum of three data points in the baseline phase were collected on parent fidelity and a decision to move to the next phase was based on the stability of the data (Horner et al., 2005; What Works Clearinghouse, 2020).

\section{Independent Variable (IV)}

P-ESDM intervention. In our rural northeastern state, parents and families of young children with autism are offered the Early Start Denver Model (Rogers \& Dawson, 2010) as an option for IDEA Part C early intervention services. For this reason, the P-ESDM was chosen as the intervention for this study because it follows the same science of applied behavior analysis and developmental, relationship-based intervention of the ESDM. The family-centered approach of P-ESDM aligns with the state's primary service provider model in which one member of the multidisciplinary team is selected to be the family's primary contact for early intervention services. Likewise, our state faces persistent personnel shortages in early childhood intervention, often cited as a barrier to accessing high quality services for families living in rural 
Effects of a parent training using telehealth: Equity and access to early intervention...

and remote areas (Martinez et al., 2018). For this reason, telehealth was chosen as the means for implementation of P-ESDM.

During the 12-weeks of P-ESDM intervention, parents were taught how to use the 10 topics of PESDM to target multiple skills within their child's daily routines and activities to strengthen and support their child's development. Examples of family routines and activities included reading a book together, eating breakfast, diaper changing, and family outings. P-ESDM topics included attention and motivation, sensory social routines, joint activity routines, nonverbal communication, imitation, joint attention, speech development, functional and symbolic play skills, and the teaching techniques of applied behavior analysis (see Table 2 for P-ESDM topics and strategies). Intervention sessions were scheduled at a time convenient for the family and conformed to the detailed parent training manual, curriculum, and parent fidelity of implementation measures (Rogers et al., 2012).

Table 2. P-ESDM topics and strategies (Adapted from Rogers et al., 2012)

\begin{tabular}{|c|c|c|}
\hline Topic & Goal & Strategy \\
\hline $\begin{array}{l}\text { Step into the spotlight: Capturing your } \\
\text { child's attention }\end{array}$ & $\begin{array}{l}\text { Increase child's attention on parent for } \\
\text { learning }\end{array}$ & $\begin{array}{l}\text { Identify and follow the child's interests, } \\
\text { reduce outside distractions that interfere } \\
\text { with child's ability to attend and } \\
\text { participate in learning opportunities }\end{array}$ \\
\hline $\begin{array}{l}\text { Find the smile: Fun with sensory social } \\
\text { routines }\end{array}$ & $\begin{array}{l}\text { Increase child's positive affect and social } \\
\text { communication behaviors using songs, } \\
\text { social games, and social exchanges }\end{array}$ & $\begin{array}{l}\text { Introduce and build a repertoire of } \\
\text { sensory social routines to optimize } \\
\text { child's energy level for learning }\end{array}$ \\
\hline $\begin{array}{l}\text { It takes two: Building back and forth } \\
\text { interactions }\end{array}$ & $\begin{array}{l}\text { Increase opportunities for child learning } \\
\text { within daily activities and routines }\end{array}$ & $\begin{array}{l}\text { Build joint activities and take turns with } \\
\text { the child, use simple words, create new } \\
\text { learning opportunities with additional } \\
\text { materials, actions, and steps to the play, } \\
\text { end the activity together and transition } \\
\text { to the next activity }\end{array}$ \\
\hline $\begin{array}{l}\text { Talking bodies: The importance of } \\
\text { nonverbal communication }\end{array}$ & $\begin{array}{l}\text { Increase child's nonverbal } \\
\text { communication skills for promoting } \\
\text { speech and language }\end{array}$ & $\begin{array}{l}\text { Add gestures, facial expressions, and } \\
\text { simple language to family activities and } \\
\text { routines. Identify communicative } \\
\text { opportunities in which the child's body } \\
\text { language can be used to express feelings } \\
\text { and interests }\end{array}$ \\
\hline $\begin{array}{l}\text { Do what I do: Helping your child learn } \\
\text { by imitating }\end{array}$ & $\begin{array}{l}\text { Increase child's imitation of sounds, } \\
\text { gestures, facial expressions, actions and } \\
\text { words }\end{array}$ & $\begin{array}{l}\text { Imitate child's play, sounds/ } \\
\text { vocalizations, and movements and } \\
\text { encourage imitation back from child } \\
\text { inside toy play, songs, social games, and } \\
\text { other daily activities }\end{array}$ \\
\hline Let's get technical: How children learn & $\begin{array}{l}\text { Teach the basic strategies of applied } \\
\text { behavior analysis for enhancing child } \\
\text { learning }\end{array}$ & $\begin{array}{l}\text { Identify and use antecedent-behavior- } \\
\text { consequence teaching principles for } \\
\text { understanding child behavior and } \\
\text { teaching new skills }\end{array}$ \\
\hline $\begin{array}{l}\text { The joint attention triangle: Sharing } \\
\text { interests with others }\end{array}$ & $\begin{array}{l}\text { Increase child's interest to share objects } \\
\text { and activities with others }\end{array}$ & $\begin{array}{l}\text { Give, show, and point to objects and } \\
\text { pictures for sharing enjoyment }\end{array}$ \\
\hline It's playtime & $\begin{array}{l}\text { Increase learning opportunities in } \\
\text { parent-child toy play and support } \\
\text { constructive, varied, and independent } \\
\text { toy play. }\end{array}$ & $\begin{array}{l}\text { Use play to build and practice skills, } \\
\text { including social skills, and to create new } \\
\text { ways to play with toys independently } \\
\text { and with others }\end{array}$ \\
\hline Let's pretend & $\begin{array}{l}\text { Develop child's pretend play that is } \\
\text { spontaneous, creative, and flexible }\end{array}$ & $\begin{array}{l}\text { Use imitation to teach symbolic play } \\
\text { actions to make scenes from life } \\
\text { activities }\end{array}$ \\
\hline Moving into speech & $\begin{array}{l}\text { Increase child's use and understanding } \\
\text { of speech through active engagement } \\
\text { with people, their facial expressions, and } \\
\text { their gestures }\end{array}$ & $\begin{array}{l}\text { Develop vocal games to increase child's } \\
\text { sounds and build up child's vocabulary } \\
\text { with more opportunities for } \\
\text { listening and responding to language }\end{array}$ \\
\hline
\end{tabular}

During the first 90-minute videoconferencing P-ESDM session, parents shared which P-ESDM topics seemed more or less relevant to their learning needs and strategies of interest that they may have read about in the parent manual. Sessions 2-12 followed a similar format and began with a brief check in. Parents shared their experience and an example of using the P-ESDM topic inside an activity or routine with their 
child. Next, the parent and the interventionist reflected about how the topic was used to support the child's development and explored ways to expand or improve the activity to increase the child's engagement and learning or to augment the child's behavior. Then a new topic was introduced, and the interventionist coached the parent through several activities with the child. Parents used Bluetooth ear buds during this part of the session so as to not distract the child with the interventionist's voice. Each session ended with the parent selecting activities and routines in which to use the new topic. After each session, parents were provided with an electronic handout of the goals and strategies taught during the session and the parentselected activities to try with their child.

\section{Interventionist Training}

Sessions were delivered by a certified P-ESDM interventionist with a master's degree and 20-years of experience in the field of early intervention. The interventionist was trained to implement P-ESDM by observing live and video-recorded intervention sessions, implementing intervention sessions, comparing self-completed fidelity checklists with trainer-completed fidelity checklists, and participating in reflection and problem-solving discussions. Before participating in the study, the interventionist achieved a fidelity rating of at least $85 \%$ or above on three video submissions as measured by the P-ESDM fidelity checklist.

\section{Dependent Variables (DVs)}

The study conducted observation coding and analyses. Primary outcome measures included parent and interventionist fidelity with a secondary outcome of pre-to post change in their child's autism symptoms as a result of parent-implementation.

\section{Parent Fidelity of Implementation}

Intervention sessions were provided with and recorded using the Zoom ${ }^{\circledR}$ video conferencing system. Recordings were observed by the interventionist following each session to measure parent fidelity using the P-ESDM Parent Fidelity Rating System. This is a Likert-type rating scale with scores ranging from level 1 (e.g. poor or unacceptable) to level 5 (e.g. best possible example) across 13 adult behaviors related to (a) management of child attention, (b) quality of behavioral teaching, (c) instructional techniques and application, (d) child affect and arousal, (e) management of unwanted behavior, (f) dyadic engagement, (g) child motivation for participating in the activity, (h) adult use of positive affect, (i) adult sensitivity and responsivity to child's communicative cues, (j) multiple and varied communicative opportunities, (k) appropriateness of adult's language for the child's language level, (l) joint activity structure and elaboration, (m) transitions between activities, and (n) child engagement during unstructured times.

\section{Interventionist Fidelity of Implementation}

To evaluate the quality of implementation, the interventionist's fidelity was examined using the PESDM Coaching Fidelity Rating System, a Likert-type rating scale with scores ranging from 1 (i.e., no competence) to level 5 (i.e., high competence) across the teaching behaviors. Fidelity was defined as no scores under 2 and a mean score of $80 \%$ or above on three consecutive coded sessions. The following activities were assessed (a) greeting and check-in, (b) warm up activity, (c) introduction of the topic, (d) coaching on the topic, (e) coaching activity 2, and (f) closing. Coaching fidelity of these behaviors were examined (g) collaborative, (h) reflective, (i) nonjudgmental, (j) conversational and reciprocal, (k) ethical conduct, (l) organization and management, and (m) managing conflict and implementation difficulties. Inter-rater agreement was defined as raters' scores falling within 1 point on the Likert-type rating scale for each item.

Reliability. Inter-observer agreement was established prior to fidelity scoring and maintained throughout the study. Two master's level and certified ESDM therapists independently rated $100 \%$ of baseline session video recordings, $30 \%$ of randomly selected intervention video recordings, and $100 \%$ of maintenance and generalization video recordings. An agreement was defined as both raters' scores being within 1-point on the Likert-type scale for each item. Inter-rater agreement was defined as raters' scores 
Effects of a parent training using telehealth: Equity and access to early intervention...

falling within 1 point on the Likert-type rating scale for each item. The goal for achievement of fidelity was $80 \%$. Inter-observer ratings in this study were $95 \%$ for parent fidelity and $94 \%$ for interventionist fidelity. See Table 3 for P-ESDM fidelity scoring instructions.

Table 3. P-ESDM fidelity rating instructions (Adapted from Rogers et al., 2012)

\begin{tabular}{ll}
\hline & Instructions to Raters \\
\hline 1 & If rating from a video recording, watch the recording in a confidential setting with minimal distractions. \\
3 & Review the child's objectives prior to coding. Keep them available to check as needed. \\
4 & Read the language defining each behavior and anchor every score. \\
5 & Take brief notes during the session you are observing in order to remember examples of behavior. \\
6 & When rating, be aware of rater biases. \\
7 & Observe each activity one time through without stopping. Make notes and replay as needed. \\
8 & the problem accordingly. \\
9 & If you are caught between two codes, then give the higher code. \\
& One is considered to have achieved fidelity to the model if they have no scores under 2 and a mean score of $80 \%$ or \\
\end{tabular}

\section{Autism Impact Measure}

Severity of children's ASD symptoms was measured using the Autism Impact Measure, a 41-item parent-report measure of core autism symptoms (see Table 7 for AIM items). Developed using a large sample of 440 children and adolescents with ASD, test-retest reliability ranged from .65 to .85 for the frequency subdomains and .53 to .78 for the impact subdomains (Kanne et al., 2014). Given these sound psychometric properties, the Autism Impact Measure was selected for the ability to track short-term improvement across clinically relevant ASD symptom domains. Items were rated on the following corresponding 5-point scales for frequency of symptom occurrence ( $1=$ never, $5=$ always) and symptomrelated impact on daily functioning ( $1=$ not at all, $5=$ severe). Positively phrased frequency items $28-41$ were reverse scored to ensure that all items reflected frequency of problematic behavior for analysis (Kanne et al., 2014, p. 173).

Social validity: Telehealth usability and acceptability questionnaire. Parents completed a program developed electronic questionnaire following the intervention phase to characterize the intervention's utility, acceptability and feasibility. Parents responded to 17 Likert-type 6-point scale questions about the usability and acceptability of the telehealth format, 18 Likert-type 6-point scale questions about their level of satisfaction with the interventionist's coaching, and three open-ended questions about the coaching process. Example Likert-type scale items (with response anchors of strongly agree, somewhat agree, somewhat disagree, and strongly disagree) included "I felt supported by the telehealth intervention and therapist coaching in spite of distance."; "Telehealth saves me time traveling for services."; "The discussion and problem solving with the coach were helpful for reaching goals.", "I think the visits provided by telehealth are the same as in-person visits.", and "I was able to use the telehealth intervention to increase my child's participation in activities and play." Open-ended questions included "What did you like best about the telehealth parent coaching?" and "What did you like least?"

\section{Procedure}

Project staff met with interested families, explained the project, and obtained informed consent from the parents. A routines-based interview (McWilliam, 2010) was completed to gather information about the family's priorities and concerns and information about their typical routines and activities.

\section{Baseline Phase}

Baseline sessions were conducted in-person. The camera setting of an iPad was used to video-record a minimum of three 10-minute play sessions between the child and parent. The iPad was set up on a table or shelf to minimize distractions. Parents were asked to interact with their child as they typically would during everyday activities, with no attempt to influence parents' behaviors. Examples of parent-child activities observed included playing with preferred toys, building with blocks, eating a snack among others. Parent fidelity of implementation of intervention strategies was measured using the P-ESDM 
Parent Fidelity Rating System (Rogers et al., 2012) by the interventionist, and no parent coaching occurred during baseline sessions. Parents were provided a copy of the parent manual, Early Start for Your Child with Autism: Using Everyday Activities to Help Kids Connect, Communicate, and Learn (Rogers et al., 2012). Additionally, the interventionist and parent worked together to set up and test-run the technology that would be used for the intervention sessions (e.g., ear buds for coaching, video-conferencing system on smart phone, tablet, or computer). Parents were provided training as needed to operate the Bluetooth ear buds and the Zoom ${ }^{\circledR}$ video conferencing system.

\section{P-ESDM Intervention Phase}

Each 90-minute intervention session followed the format of the manualized P-ESDM intervention. Sessions were video recorded using the Zoom ${ }^{\circledR}$ video conferencing system. Parent fidelity was measured during the warm-up activity for previously taught strategies and during the coaching activity for new strategies. Parents were encouraged to use the strategies in their everyday activities with their child; however, there were no specific requirements given to parents about the frequency and duration that parents should use to implement the intervention strategies. Parents completed the telehealth usability and acceptability questionnaire following the intervention phase.

\section{Maintenance Phase}

The interventionist observed the family interacting with their child as they typically would during activities and play two weeks after intervention sessions were completed as a maintenance measure of the parent's fidelity of intervention strategies. Parent fidelity of implementation of intervention strategies was measured using the P-ESDM Parent Fidelity Rating System by the interventionist, but no parent coaching occurred during these sessions. This 90-minute telehealth session was video recorded.

\section{Generalization Phase}

Two weeks following the maintenance session, parents were invited to submit a 10-20- minute video recording to measure generalization of parent fidelity of implementation of intervention strategies. Parent fidelity of implementation of intervention strategies was measured using the P-ESDM Parent Fidelity Rating System by the interventionist, but no parent coaching occurred during these sessions.

\section{Data Analysis}

The functional relationship between the P-ESDM via telehealth intervention and dependent variable of parent fidelity of intervention strategies was analyzed through visual inspection and descriptive statistics of graphed data. The level, trend, variability of data across phases, and single case measures of effect for each participant provided the context for the analysis (Kratochwill et al., 2010).

Data on dependent measures was analyzed using nonoverlap of all pairs (NAP), TAU-U, and percent non overlapping data (PND). NAP is a nonparametric measure of effect for measuring nonoverlap or between two phases. It does not include adjustment for data trends in baseline (Scruggs \& Mastropieri, 1998). TAU-U is a nonparametric measure to measure data overlap between phases. It allows for analysis adjustment for baseline trends and is a measure that can distinguish how much of the nonoverlap was an improvement over baseline. It is a way to determine whether or not improvement was due to the intervention versus chance (Parker, Vannest, \& Davis, 2011). The PND was calculated using the following formula: the number of intervention data points that surpassed the highest baseline data point divided by the total number of intervention data points, then multiplied by 100 (Scruggs, Mastropieri, \& Casto, 1987). Scruggs and Mastropieri (2001) suggested interpretational guidelines of PND when used to evaluate the effectiveness of the intervention. Using their guidelines, authors evaluated PND greater than $90 \%$ as a highly effective intervention, PND greater than $70 \%$ and less than $90 \%$ as an effective intervention, PND greater than $50 \%$ and less than $70 \%$ as questionable effectiveness, and PND less that $50 \%$ was considered unreliable effectiveness for interventions.

Statistical analyses of the pre-post Autism Impact Measure responses were performed using SPSS Statistics version 25. Positively phrased frequency items were reverse scored, so that "all items reflected 
Effects of a parent training using telehealth: Equity and access to early intervention...

frequency of problematic behavior" (Kanne et al., 2014, p. 173). In addition to descriptive statistics, the Wilcoxon Signed-rank test was conducted. The Wilcoxon is a non-parametric statistical hypothesis test used to compare two repeated measurements on a single sample to determine if mean ranks differ. This non-parametric test was chosen because 1) the pre-post responses were measured at the ordinal level using Likert scale questions, 2) the responses consisted of related pairs, and 3) given the sample size, the population was not assumed to be a normal distribution.

\section{Results}

\section{Parent Fidelity}

Parents' fidelity of implementation of P-ESDM are reported in Figure 1 (see Appendix A) and Tables 4 and 5. The intervention was delivered in one group of four families and two groups of three families. Group 1 included families identified as F1, F2, F3 and F4, group 2 included families identified as F5, F6, and F7, and group 3 included families identified as F8, F9, and F10.

Data collected during the first three weeks indicated that the four families' fidelity of implementation of the P-ESDM intervention strategies (F1, F2, F3, F4) ranged from $40 \%$ to $65 \%$ during baseline. Figure 1 shows a graphical display of these data. After a stable baseline, Family 1 showed minimal change and a moderate amount of variability in implementation fidelity data beginning in session three of the intervention. Maintenance data for Family 1 does indicate an increase in fidelity compared to baseline levels, however a functional relationship was not established due to the lack of immediacy of change. For family F1, the implementation of P-ESDM intervention resulted in a marked increased parent fidelity after the sixth intervention session (baseline $M=60 \%$, intervention $M=68 \%$ ). Single case design (SCD) measures of effect indicate that the intervention had a moderate effect: PND \& NAP $=83 \%$; TAU $=0.67, z=1.73, p=$ .08. The trend for intervention data was stable. These gains were maintained at an even higher rate (maintenance $=82 \%$ ) when measured two weeks after completion of the P-ESDM intervention.

However, after a baseline with a decreasing trend, the fidelity of parent implementation of the PESDM intervention increased immediately and markedly for Family 2 after the introduction of the telehealth P-ESDM intervention. A functional relationship was established due to the immediacy of change. Family F2 had a decreasing trend during baseline fidelity collection $(\mathrm{M}=43 \%)$ that increased when the PESDM intervention was introduced $(\mathrm{M}=72 \%)$. Yet, SCD measures of effect indicate that the intervention demonstrated a large effect: $\mathrm{PND} \& \mathrm{NAP}=100 \%$; $\mathrm{TAU}=1.0, \mathrm{z}=1.73, \mathrm{p}=.009$. Although intervention data was variable, this change in level was maintained, and then generalized at levels above those of baseline, demonstrating a therapeutic effect. These gains were maintained at an even higher rate (maintenance = 87\%) when measured two weeks after completion of the P-ESDM intervention via telehealth. At generalization 8 weeks following the maintenance session, the parent fidelity for family F2 continued to be above the intervention mean (generalization $=80 \%$ ).

Likewise, family F3 had a stable, but decreasing trend during baseline fidelity collection (M=39\%) that increased markedly, although not until the second session of the P-ESDM intervention (M=70\%) limiting the interpretation of a functional relationship and the immediacy of effect of the treatment. Yet, SCD measures of effect indicate that the intervention demonstrated a large effect: $P N D=92 \%, N A P=96 \%$, $\mathrm{TAU}=1.0, \mathrm{z}=2.60, \mathrm{p}=.009$. Intervention data was relatively stable, and gains were maintained at a rate higher than baseline levels (maintenance $=83 \%$ ) when measured two weeks after completion of the PESDM intervention.

Family F4 had a decreasing trend during baseline fidelity collection ( $\mathrm{M}=74 \%)$ that increased only after the third intervention session $(\mathrm{M}=78 \%)$ limiting the interpretation of a functional relationship and the immediacy of effect of the treatment. Similarly, SCD measures of effect indicate that the intervention demonstrated a questionable effect: $\mathrm{PND}=41 \%, \mathrm{NAP}=63 \%, \mathrm{TAU}=0.33, \mathrm{z}=.866, \mathrm{p}=.39$. However, when parent fidelity was collected at maintenance, there was an increased fidelity score (maintenance $=93 \%$ ). At generalization eight weeks following the maintenance session, the parent fidelity for family F4 continued 
to be above the intervention mean (generalization $=85 \%$ ) but did overlap with much of the intervention data.

The following three families' data (F5, F6, and F7) across four weeks of baseline indicate similar results and their fidelity of implementation of the P-ESDM intervention strategies ranged from $48 \%$ to $63 \%$ during baseline. All three of these families also demonstrated an increase in P-ESDM fidelity of implementation. After a baseline with a decreasing trend for family F5, the implementation of P-ESDM intervention resulted in a marked increased parent fidelity, but only after the fourth intervention session (baseline $\mathrm{M}=57 \%$, intervention $\mathrm{M}=67 \%$ ) limiting the interpretation of a functional relationship and the immediacy of effect of the treatment. Yet, SCD measures of effect indicate that the intervention had a moderate effect, $\mathrm{PND}=75 \%, \mathrm{NAP}=83 \%, \mathrm{TAU}=0.67, \mathrm{z}=1.73, \mathrm{p}=.08$ and intervention data indicate an increasing trend. These gains were maintained (maintenance $M=65 \%$ ) when measured two weeks after completion of the P-ESDM intervention.

Family F6 had a stable baseline ( $M=63 \%)$ that increased immediately, then markedly after the fourth intervention session to a Mean of $81 \%$ demonstrating a weak effect based on visual analysis alone. Yet, SCD measures of effect indicate that the intervention had a large effect, PND \& NAP $=100 \%$; TAU $=1.0, z=2.60$, $\mathrm{p}=.009$, and intervention data were relatively stable. These gains were maintained at a higher rate of fidelity (maintenance $=97 \%$ ) when measured two weeks after completion of the P-ESDM intervention.

Family F7 had an increasing baseline, and the fidelity of implementation of P-ESDM increased during intervention sessions (baseline $\mathrm{M}=48 \%$, intervention $\mathrm{M}=73 \%$ ) limiting the interpretation of a functional relationship and the immediacy of effect of the treatment. Yet, SCD measures of effect indicate that the intervention had a large effect, PND \& NAP $=100 \%, \mathrm{TAU}=0.91, \mathrm{z}=2.38, \mathrm{p}=.0172$ ). These gains were maintained at an even higher rate of fidelity (maintenance $=80 \%$ ) when measured two weeks after completion of the P-ESDM coaching via telehealth intervention. At generalization eight weeks following the maintenance session, the parent fidelity for family F7 continued to be above the intervention mean (generalization $=82 \%$ ).

Baseline was conducted across five weeks for the final three families (F8, F9, and F10). The fidelity of implementation of the P-ESDM intervention strategies for these three families ranged from $50 \%$ to $55 \%$ during baseline. All three of these families demonstrated increased parent fidelity of implementation of PESDM after the introduction of the intervention.

For family F8, after a variable baseline, the implementation of P-ESDM intervention resulted in a marked and immediate increased parent fidelity (baseline $M=55 \%$, intervention $M=74 \%$ ) with a relatively stable trend, indicating therapeutic effects. Yet, SCD measures of effect indicate that the intervention had the following effects: PND $=67 \%$ (questionable effect), NAP $=93 \%$ (large effect); TAU $=0.83, z=1.17, p=$ .03 (large effect). Therapeutic gains were maintained at a higher rate of fidelity (maintenance $=83 \%$ ) when measured two weeks after completion of the P-ESDM intervention.

After a stable baseline $(\mathrm{M}=50 \%)$, the data for family F9 increased immediately with a variable trend during intervention ( $\mathrm{M}=67 \%$ ) indicating small therapeutic effects. Yet, SCD measures of effect indicate that the intervention had the following effect: $\mathrm{PND}=83 \%$ (moderate effect), NAP=93\% (large effect); TAU $=0.88, \mathrm{z}=2.30, \mathrm{p}=.02$ (large effect). Therapeutic gains were maintained at a higher rate of fidelity (maintenance $=78 \%$ ) when measured two weeks after completion of the P-ESDM intervention and at generalization 8 weeks following the maintenance session (generalization $M=92 \%$ ).

Lastly, family F10 had a stable baseline $(\mathrm{M}=54 \%)$ that also increased, but not until the fourth session of intervention to a mean of $70 \%$ with moderate variability, limiting the interpretation of a functional relationship and the immediacy of effect of the treatment. Yet, SCD measures of effect indicate that the intervention had the following effect: $\mathrm{PND}=83 \%$ (moderate effect), NAP $=96 \%$ (large effect); TAU $=0.92$, $\mathrm{z}=2.38, \mathrm{p}=.017$ (large effect). Gains in mean fidelity ratings were maintained at a higher rate of fidelity (maintenance $\mathrm{M}=85 \%$ ) when measured two weeks after completion of the P-ESDM intervention, and at generalization 8 weeks later the parent fidelity for family F10 continued to be above the intervention mean 
Effects of a parent training using telehealth: Equity and access to early intervention...

(generalization $\mathrm{M}=90 \%$ ). Table 4 displays the single case design measure of effect for parent fidelity and mean coaching fidelity. Table 5 displays the mean baseline versus intervention parent fidelity.

Table 4. Parent fidelity single case design measure of effect and coaching fidelity

\begin{tabular}{|c|c|c|c|c|}
\hline Family & $\begin{array}{l}\text { Baseline to Intervention } \\
\text { PND }\end{array}$ & $\begin{array}{c}\text { Baseline to Intervention } \\
\text { NAP }\end{array}$ & $\begin{array}{l}\text { TAU-U Baseline to } \\
\text { Intervention }\end{array}$ & $\begin{array}{c}\text { Mean Coaching } \\
\text { Fidelity }\end{array}$ \\
\hline F1 & $\begin{array}{c}83 \% \\
\text { Moderate Effect }\end{array}$ & $\begin{array}{c}83 \% \\
\text { Moderate Effect }\end{array}$ & $\begin{array}{c}0.67 \\
z=1.73 \\
p=.08\end{array}$ & $92 \%$ \\
\hline F2 & $\begin{array}{c}100 \% \\
\text { Large Effect }\end{array}$ & $\begin{array}{c}100 \% \\
\text { Large Effect }\end{array}$ & $\begin{array}{c}1.0 \\
z=1.73 \\
* p=.009\end{array}$ & $90 \%$ \\
\hline F3 & $\begin{array}{c}92 \% \\
\text { Large Effect }\end{array}$ & $\begin{array}{c}96 \% \\
\text { Large Effect }\end{array}$ & $\begin{array}{c}1.0 \\
z=2.60 \\
* p=.009\end{array}$ & $90 \%$ \\
\hline F4 & $\begin{array}{c}41 \% \\
\text { Questionable } \\
\text { Effect }\end{array}$ & $\begin{array}{c}63 \% \\
\text { Questionable } \\
\text { Effect }\end{array}$ & $\begin{array}{c}.33 \\
z=.866 \\
p=.39\end{array}$ & $92 \%$ \\
\hline F5 & $\begin{array}{c}75 \% \\
\text { Moderate Effect }\end{array}$ & $\begin{array}{c}83 \% \\
\text { Moderate Effect }\end{array}$ & $\begin{array}{c}.67 \\
z=1.73 \\
p=.08\end{array}$ & $88 \%$ \\
\hline F6 & $\begin{array}{c}100 \% \\
\text { Large Effect }\end{array}$ & $\begin{array}{c}100 \% \\
\text { Large Effect }\end{array}$ & $\begin{array}{c}1.0 \\
z=2.60 \\
{ }^{*} p=.009\end{array}$ & $91 \%$ \\
\hline F7 & $\begin{array}{c}100 \% \\
\text { Large Effect }\end{array}$ & $\begin{array}{c}100 \% \\
\text { Large Effect }\end{array}$ & $\begin{array}{c}.91 \\
z=2.38 \\
{ }^{*} p=.017\end{array}$ & $93 \%$ \\
\hline F8 & $\begin{array}{c}67 \% \\
\text { Questionable } \\
\text { Effect }\end{array}$ & $\begin{array}{c}93 \% \\
\text { Large Effect }\end{array}$ & $\begin{array}{c}0.83 \\
z=1.17 \\
* p=.03\end{array}$ & $93 \%$ \\
\hline F9 & $\begin{array}{c}83 \% \\
\text { Moderate Effect }\end{array}$ & $\begin{array}{c}93 \% \\
\text { Large Effect }\end{array}$ & $\begin{array}{c}0.88 \\
z=2.30 \\
{ }^{*} p=.02\end{array}$ & $91 \%$ \\
\hline F10 & $\begin{array}{c}83 \% \\
\text { Moderate Effect }\end{array}$ & $\begin{array}{c}96 \% \\
\text { Large Effect }\end{array}$ & $\begin{array}{c}0.92 \\
z=2.38 \\
{ }^{*} p=.017\end{array}$ & $90 \%$ \\
\hline
\end{tabular}

Table 5. Mean baseline as compared to intervention parent fidelity

\begin{tabular}{|c|c|c|c|c|}
\hline Family & $\begin{array}{c}\text { Mean } \\
\text { Baseline Fidelity }\end{array}$ & $\begin{array}{c}\text { Mean } \\
\text { Intervention Fidelity }\end{array}$ & $\begin{array}{c}\text { Maintenance } \\
\text { Fidelity }\end{array}$ & $\begin{array}{c}\text { Generalization } \\
\text { Fidelity }\end{array}$ \\
\hline F1 & $60 \%$ & $68 \%$ & $82 \%$ & $\mathrm{NA}$ \\
\hline F2 & $43 \%$ & $72 \%$ & $87 \%$ & $80 \%$ \\
\hline F3 & $39 \%$ & $70 \%$ & $83 \%$ & NA \\
\hline $\mathrm{F} 4$ & $74 \%$ & $78 \%$ & $93 \%$ & $85 \%$ \\
\hline F5 & $57 \%$ & $67 \%$ & $65 \%$ & NA \\
\hline F6 & $63 \%$ & $81 \%$ & $97 \%$ & NA \\
\hline F7 & $48 \%$ & $73 \%$ & $80 \%$ & $82 \%$ \\
\hline F8 & $55 \%$ & $74 \%$ & $83 \%$ & NA \\
\hline F9 & $50 \%$ & $67 \%$ & $78 \%$ & $92 \%$ \\
\hline F10 & $54 \%$ & $70 \%$ & $85 \%$ & $90 \%$ \\
\hline AVERAGE & $54 \%$ & $72 \%$ & $83.30 \%$ & $85.80 \%$ \\
\hline
\end{tabular}

\section{Telehealth Usability and Acceptability}

Parents rated the 17 items on the program developed Telehealth Usability and Acceptability Questionnaire with strongly agree, agree and somewhat agree. Parents felt well supported by the telehealth intervention and coaching process with $88.89 \%$ (8/9) strongly agreeing and $11.11 \%(1 / 9)$ agreeing with the statement. Parents selected strongly agree with 100\% (9/9) being satisfied with the telehealth intervention. Parents felt the intervention increased their child's participation in activities and play with $100 \%(9 / 9)$ reporting as strongly agree. Additionally, parents reported that the intervention was effective in helping the parent create solutions for their child with $88.89 \%$ (8/9) strongly agreeing and $11.11 \%(1 / 9)$ agreeing 
with the statement. Overall, parents reported they would use the telehealth services again with $77.78 \%$ (7/9) strongly agreeing and $22.22 \%(2 / 9)$ agreeing with this statement.

Parents responded to three open-ended questions. One parent summed up their experience with the P-ESDM intervention via telehealth intervention by responding, "It helped me gain so much insight and knowledge about how to effectively play and interact with my child. I loved the book that was provided to me and found it an extremely helpful resource.". Another parent indicated the intervention's impact by responding,

I felt I was learning and using skills that were making a difference in my life as a ...parent giving me confidence that I could give our little one a real chance to be happy and healthy and to have the best shot at a full and rewarding life. Being the person doing the work, studying and applying the knowledge makes this a life changer not just a program that is carried out by someone else and ends and is forgotten. Any child and parent willing to commit to this program would have long term benefits. It's a life solution not just a short-term intervention.

Families reported that the intervention conducted in their homes was convenient, and commented positively on the interventionist's insight, input, support and suggestions provided during videoconferencing, "The guidance (of the interventionist) helped me expand my tools to help me help my child.".

\section{Autism Impact Measure}

Pre-to-post change in autism symptomatology for child participants was examined. A Wilcoxon Signed-rank test revealed a statistically significant reduction in frequency of reported problematic behaviors after participating in the P-ESDM intervention, $\mathrm{z}=2.35, \mathrm{p}=.019$, with a large effect size $(\mathrm{r}=.53)$. The median frequency score decreased from pre-intervention $(\mathrm{Mdn}=91.0, \mathrm{SD}=20.30)$ to post-intervention $(\mathrm{Mdn}=75.5, \mathrm{SD}=11.44)$, indicating a positive change. Additionally, the Wilcoxon Signed-rank test revealed a statistically significant reduction of the impact of problematic behaviors on everyday activities after participating in the P-ESDM intervention, $\mathrm{z}=2.55, \mathrm{p}=.011$, with a large effect size $(\mathrm{r}=.57)$. The median impact score decreased from pre-intervention $(\mathrm{Mdn}=67.0, \mathrm{SD}=21.51)$ to post-intervention $(\mathrm{Mdn}=54.4$, $\mathrm{SD}=12.09$ ). To further answer the research questions, the difference between means was examined for each item. We report on statistically significant items below. Because of the small sample, we use Hedges' $\mathrm{g}$ to report the effect size. See Table 6 for statistically significant items and Appendix B for items, means, standard deviations, difference between means and $\mathrm{p}$ values.

Table 6. Statistically significant items and difference between means of the autism impact measure

\begin{tabular}{|c|c|c|c|c|c|c|c|c|}
\hline \multirow[t]{2}{*}{ Item\# } & \multirow[t]{2}{*}{ Item } & \multicolumn{2}{|c|}{ Pre-Intervention } & \multicolumn{2}{|c|}{ Post-Intervention } & \multirow[b]{2}{*}{$M$ difference } & \multirow[b]{2}{*}{$p$} & \multirow[b]{2}{*}{$g$} \\
\hline & & $M$ & $\mathrm{SD}$ & $M$ & SD & & & \\
\hline \multicolumn{9}{|c|}{ Frequency Items } \\
\hline 5 & $\begin{array}{l}\text { Used someone else's hand to point, } \\
\text { touch or perform a task }\end{array}$ & 2.60 & 1.65 & 1.70 & .823 & 0.90 & *.041 & .69 \\
\hline 14 & $\begin{array}{l}\text { Experienced problems in } \\
\text { communicating with others }\end{array}$ & 4.30 & .949 & 2.80 & .789 & 1.50 & $* .004$ & 1.72 \\
\hline 22 & Resisted changes in routines & 2.50 & 1.58 & 1.40 & .966 & 1.10 & *.014 & .84 \\
\hline 26 & $\begin{array}{l}\text { Experienced problems in social } \\
\text { interactions }\end{array}$ & 3.10 & 1.37 & 2.50 & 1.18 & .60 & $* .034$ & .47 \\
\hline$\wedge 30$ & $\begin{array}{l}\text { Shared his enjoyment or excitement } \\
\text { with others }\end{array}$ & 1.60 & 1.07 & 2.50 & 1.43 & .90 & $* .034$ & .71 \\
\hline$\wedge 33$ & $\begin{array}{l}\text { Used a social smile to greet people or } \\
\text { respond to them }\end{array}$ & 1.60 & 1.07 & 2.70 & 1.57 & 1.10 & $* .026$ & .82 \\
\hline$\wedge 34$ & Used gestures to communicate & 2.30 & 1.16 & 3.80 & 1.23 & 1.50 & *.006 & 1.25 \\
\hline$\wedge 36$ & $\begin{array}{l}\text { Seemed interested in other children } \\
\text { his age }\end{array}$ & 2.33 & 1.58 & 3.20 & 1.75 & .87 & $* .008$ & .52 \\
\hline \multicolumn{9}{|c|}{ Impact Items } \\
\hline 7 & $\begin{array}{l}\text { Had certain rituals or routines that } \\
\text { have to be followed }\end{array}$ & 2.00 & 1.41 & 1.40 & .843 & .60 & *.034 & .52 \\
\hline 18 & $\begin{array}{l}\text { Experienced problems in } \\
\text { communicating with others }\end{array}$ & 4.00 & 1.25 & 2.70 & .823 & 2.30 & $* .010$ & 1.23 \\
\hline 22 & Resisted changes in routines & 2.40 & 1.43 & 1.50 & 1.08 & .900 & *.024 & .71 \\
\hline$\wedge 41$ & Made eye contact with others & 1.60 & .966 & 2.70 & 1.25 & 1.10 & ${ }^{*} .026$ & .98 \\
\hline
\end{tabular}


Effects of a parent training using telehealth: Equity and access to early intervention...

$\wedge$ denotes reverse scored items

Social reciprocity. A statistically significant difference between means was found for several items in the social reciprocity domain. Following the intervention, parents reported their child shared enjoyment or excitement with others (pre- $\mathrm{M}=1.60, \mathrm{SD}=1.07$; post- $\mathrm{M}=2.50, \mathrm{SD}=1.43, \mathrm{p}=.034$ ), used a social smile to greet or respond to people (pre- $\mathrm{M}=1.60, \mathrm{SD}=1.07$; post- $\mathrm{M}=2.70, \mathrm{SD}=1.57, \mathrm{p}=.026$ ), used gestures to communicate (pre- $\mathrm{M}=2.30, \mathrm{SD}=1.16$; post- $\mathrm{M}=3.80, \mathrm{SD}=1.23, \mathrm{p}=.006$ ), and seemed interested in other children of a similar age (pre- $\mathrm{M}=2.33, \mathrm{SD}=1.58$; post- $\mathrm{M}=3.20, \mathrm{SD}=1.75, \mathrm{p}=.008$ ). Children also had problems with social interactions less frequently (pre- $\mathrm{M}=3.10, \mathrm{SD}=1.37$; post- $\mathrm{M}=2.50, \mathrm{SD}=1.18, \mathrm{p}=$ $.034)$.

Communication and language. A statistically significant difference between means was found for two language and communication items, indicating positive change in children's communication behaviors. Parents reported their child used someone else's hand to point, touch or perform a task less frequently following the intervention (pre- $\mathrm{M}=2.60, \mathrm{SD}=1.65$; post- $\mathrm{M}=1.70, \mathrm{SD}=.823, \mathrm{p}=.041$ ). Children experienced problems in communicating with others less frequently (pre- $\mathrm{M}=4.30, \mathrm{SD}=.949 ;$ post- $\mathrm{M}=$ $2.80, \mathrm{SD}=.789, \mathrm{p}=.004$ ) and with less impact on their daily functioning (pre- $\mathrm{M}=4.00, \mathrm{SD}=1.25 ; \mathrm{post}-\mathrm{M}=$ $2.70, \mathrm{SD}=.823, \mathrm{p}=.010)$.

Repetitive behaviors and restricted interests. Parents reported their child was less resistant to change in routines (pre- $\mathrm{M}=2.50, \mathrm{SD}=1.58$; post- $\mathrm{M}=1.40, \mathrm{SD}=.966, \mathrm{p}=.014$ ) and that change in routines had less impact on their child's daily functioning (pre- $\mathrm{M}=2.40, \mathrm{SD}=1.43$; post- $\mathrm{M}=1.50, \mathrm{SD}=.900$, $\mathrm{p}=$ .024). In addition, a child's certain rituals or routines were reported to have less impact on their child's daily functioning (pre- $\mathrm{M}=2.00, \mathrm{SD}=1.41$; post- $\mathrm{M}=1.40, \mathrm{SD}=.843, \mathrm{p}=.034$ ).

\section{Conclusion and Discussion}

The current study investigated the effects of the P-ESDM as implemented by an early interventionist present within the state's existing IDEA Part C early intervention program. Telehealth technology was used to coach parents to conduct the intervention procedures, and all families demonstrated an increased level of implementation fidelity of the P-ESDM intervention as compared to baseline levels. The study demonstrated that positive outcomes for very young children with ASD can be achieved when parents are trained to use this naturalistic developmental behavioral intervention within and across family routines and activities. The results are among the first to demonstrate the feasibility of statewide implementation of P-ESDM in natural environments within the framework of a state's early intervention program.

The results of the current study are promising. First, the results extend support for parent-mediated early intervention for toddlers with autism. Next, the results align with previous research about P-ESDM and highlight that this low dosage intervention may be adequate to sustain intervention effects. Next, a functional relationship existed between parent fidelity of P-ESDM intervention strategies and parent participation in P-ESDM training, expanding the literature on the use of telehealth to deliver early intervention services for families, specifically in rural and underserved areas.

\section{Parent-mediated early intervention}

Parent-mediated interventions develop a parent's capacity to implement evidence-based strategies with their child. In fact, these interventions are based on the assumption that parents will implement the target strategies within their daily routines and activities with their child; thereby increasing the opportunities provided to the child to interact and engage with peers, others, and the environment (Siller \& Morgan, 2018). In the current study, parents reported statistically significant positive change in their child's autism symptoms, specifically in the domains of communication, social reciprocity and repetitive behaviors and restricted interests. These results are in agreement with the hypothesis that early intervention for toddlers at risk or diagnosed with ASD may "remit or reduce the expression of symptoms" (Webb, Jones, Kelly \& Dawson, 2014). This is promising given that even moderate and non-significant gain in ASD symptom severity post-intervention have resulted in a significant reduction of symptom severity 
one year (Green et al., 2017) and two years (Estes et al., 2014) following the conclusion of the intervention.

\section{Increased Fidelity of P-EDSM}

Maintenance is often noted to be lacking in studies of parent-mediated interventions, limiting the ability to determine sustained implementation or potential outcomes (Fettig, Barton, Carter, \& Eisenhower, 2016; Roberts \& Kaiser, 2011). In this study, parent fidelity of implementation was shown to increase during the generalization and maintenance phases; a possible assurance that parents' sustained implementation may likely impact the child's developmental trajectory and targeted communication and social behaviors over time. This "real life" intensity of services is necessary for significant change in toddlers with ASD, and these results are congruent with other researchers who have demonstrated that parent involvement helps to facilitate generalization across environments (Brian et al., 2017; McIntyre \& Zemantic, 2017; Wallace \& Rogers, 2010).

\section{Telehealth}

A functional relationship between the P-ESDM via telehealth intervention and parent fidelity of intervention strategies was demonstrated. This result is consistent with literature that telehealth can be used as a mechanism to deliver naturalistic developmental behavioral interventions and achieve positive child outcomes (McIntyre \& Zemantic, 2017; Wainer \& Ingersoll, 2015). In rural areas, equity and access to early intervention and parent coaching services can be a challenge (Olsen, Fiechtl, \& Rule, 2012). The results of this study are encouraging in that they show that parents can be coached to implement evidence-based practices at a high level of fidelity using telehealth. Providing intervention using telehealth as a service delivery model may alleviate higher costs of services associated with travel time, distance between families, and provider shortages (Little, Wallisch, Pope, \& Dunn, 2018; Olsen et al., 2012). Findings from this study suggest the use of telehealth coaching may be an equitable response to a family's limited access to professional support due to rural location. Likewise, social validity is imperative when determining the feasibility and utility of the parent training. Parents in this study expressed high satisfaction with the telehealth delivery of the P-ESDM and the intervention procedures.

\section{Limitations}

The study had several limitations. First, cellular and broadband access were a challenge in very rural areas. This did not prevent family participation, but two parents did note that an intermittent connection interfered with the video stream and the ability to clearly hear and see the interventionist. Next, the fidelity of implementation measure was coded by two providers who were trained and certified to implement ESDM procedures; however, this was not a blind review, which could have hindered the validity of their coding. Although we report large effect sizes, the analysis to examine pre to post change in autism symptomatology was limited to a non-parametric test, and we did not control for other outcomes such as age or gender. Likewise, the sample was not highly diversified, limiting generalization of the results to the participants of the study. It is also important to note that the AIM is a parent report measure, and as such is subject to potential informant bias.

Applied research is difficult to control for all potential confounding variables. Generally, all families in this study did demonstrate an increased level of fidelity in implementing the P-ESDM intervention compared to baseline levels. However, due to increasing and decreasing trends in the baseline data of many families, and the lack of immediate effect of the intervention, more research is needed to determine the functional relationship of the delivery of parent coaching via telehealth on the increase in parent fidelity to rule out maturity and test-retest effects.

\section{Future Research}

Increasing the availability of evidence-based interventions through telehealth may be a valid solution to closing the gap between service demand and availability in rural and underserved areas. Other 
Effects of a parent training using telehealth: Equity and access to early intervention...

studies have demonstrated effective results with telehealth as a service delivery model for behavioral consultation services as compared with on-site coaching (Suess, Wacker, Schwartz, Lustig, \& Detrick, 2016; Wacker et al., 2013). More research examining the comparative effectiveness of P-ESDM versus other models is needed.

In this study, parent fidelity increased during maintenance and generalization, and positive longterm effects of parent-mediated interventions have been reported to be sustained up to 6 years following the end of the intervention (Green et al., 2017; Pickles et al., 2016). Continued research is needed to examine long-term effects of parent fidelity to support increased improvement of autism symptoms and the developmental trajectories for toddlers with autism.

Intervention that builds parent capacity and supports children's development and learning through the use of evidence-based practices in everyday activities can lead to positive parent and child outcomes. In the current study, the interventionist was nationally certified to implement P-ESDM. More research is needed to examine P-ESDM and other parent-mediated interventions implemented by primary service providers who receive state-level training and support but may not be nationally certified by the agency representing the intervention.

\section{Declarations}

\section{Acknowledgements: Not applicable.}

Authors' contributions: DLRE provided table data. SKH provided figure data. SB implemented the intervention. DLRE, MK and ES provided relevant literature. All authors wrote and reviewed the manuscript.

Competing interests: The authors declare that they have no competing interests.

Funding: Partial support for this research was provided by a grant from the state Department of Education.

\section{References}

American Psychiatric Association. (2013). Diagnostic and statistical manual of mental disorders (5 $5^{\text {th }}$ ed.). American Psychiatric Publishing. https://doi.org/10.1176/appi.books.9780890425596

Ashburner, J., Vickerstaff, S., Beetge, J., \& Copley, J. (2016). Remote versus face-to-face delivery of early intervention programs for children with autism spectrum disorders: Perceptions of rural families and service providers. Research in Autism Spectrum Disorders, 23, 1-14. https://doi.org/10.1016/j.rasd.2015.11.011

Baggett, K. M., Davis, B., Feil, E. G., Sheeber, L. L., Landry, S. H., Carta, J. J., \& Leve, C. (2010). Technologies for expanding the reach of evidence-based interventions: Preliminary results for promoting social-emotional development in early childhood. Topics in Early Childhood Special Education, 29(4), 226-238. https://doi.org/10.1177/0271121409354782

Bearss, K., Burrell, T. L., Challam S. A., Postorino, V., Gillespie, S. E., Crooks, C., \& Scahill, L. (2018). Feasibility of parent training via telehealth for children with autism spectrum disorder and disruptive behavior: A demonstration pilot. Journal of Autism and Developmental Disorders, 48(4), 1020-1030. https://doi.org/10.1007/s10803-017-3363-2

Bearss, K., Burrell, T. L., Stewart, L., \& Scahill, L. (2015). Parent training in autism spectrum disorder: What's in a name? Clinical Child and Family Psychology Review, 18(2), 170-182. https://doi.org/10.1007/s10567-015-0179-5

Beaudoin, A. J., Sébire, G., \& Couture, M. (2019). Parent-mediated intervention tends to improve parent-child engagement, and behavioral outcomes of toddlers with ASD-positive screening: A randomized crossover trial. Research in Autism Spectrum Disorders, 66, 1-12. https://doi.org/10.1016/j.rasd.2019.101416

Brian, J. A., Smith, I. M., Zwaigenbaum, L., \& Bryson, S. E. (2017). Cross-site randomized control trial of the social ABCs caregivermediated intervention for toddlers with autism spectrum disorder. Autism Research, 10(10), 1700-1711. https://doi.org/10.1002/aur.1818

Caron, V., Bérubé, A., \& Paquet, A. (2017). Implementation evaluation of early intensive behavioral intervention programs for children with autism spectrum disorders: A systematic review of studies in the last decade. Evaluation and Program Planning, 62, 1-8. https://doi.org/10.1016/j.evalprogplan.2017.01.004

Chawarska, K., Macari, S. L., Volkmar, F. R., Kim, S. H., \& Shic, F. (2014). Autism and the autism spectrum: Diagnostic concepts. In F. R. Volkmar, R. Paul, S. J. Rogers, \& K. A. Pelphrey, (Eds.), Handbook of autism and pervasive developmental disorders (4 $4^{\text {th }} \mathrm{ed} ., \mathrm{pp}$. 3-27). Wiley. https://doi.org/10.1002/9781118911389 
Deborah L. ROOKS-ELLIS et al.

Estes, A., Vismara, L., Mercado, C., Fitzpatrick, A., Elder, L., Greenson, J., ... Rogers, S. (2014). The impact of parent-delivered intervention on very young children with autism. Journal of Autism and Developmental Disorders, 44(2), 353-365. https://doi.org/10.1007/s10803-013-1874-z

Fettig, A., Barton, E. E., Carter, A. S., \& Eisenhower, A. S. (2016). Using e-Coaching to support an early intervention provider's implementation of a functional assessment-based intervention. Infants $\mathcal{E}$ Young Children, 29(2), 130-147. https://doi.org/10.1097/IYC.0000000000000058

Fettig, A., \& Ostrosky, M. M. (2011). Collaborating with parents in reducing children's challenging behaviors: Linking functional assessment to intervention. Child Development Research, Article ID 835941, 1-10. https://doi.org/10.1155/2011/835941

Green, J., Pickles, A., Pasco, G., Bedford, R., Wan, M.W., Elsabbagh, M., ... Johnson, M. (2017). Randomised trial of a parent-mediated intervention for infants at high risk for autism: Longitudinal outcomes to age 3 years. The Journal of Child Psychology and Psychiatry, 58(12), 1330-1340. https://doi.org/10.1111/jcpp.12728

Horner, R. H., Carr, E. G., Halle, J., McGee, G., Odom, S., \& Wolery, M. (2005). The use of single-subject research to identify evidencebased practice in special education. Exceptional Children, 71(2), 165-179. https://doi.org/10.1177/001440290507100203

Hyman, S. L., Levy, S. E., \& Myers, S. M. (2020). AAP Council on children with disabilities, section on developmental and behavioral pediatrics: Identification, evaluation, and management of children with autism spectrum disorder. Pediatrics, 145(1), 1-64. https://doi.org/10.1542/peds.2019-3447

Individuals with Disabilities Education Act, 20 U.S.C. § 1400 (2004). Retrived from https://sites.ed.gov/idea/

Kanne, S. M., Mazurek, M. O., Sikora, D., Bellando, J., Branum-Martin, L., Handen, B., ... Warren, Z. (2014). The autism impact measure (AIM): Initial development of a new tool for treatment outcome measurement. Journal of Autism and Developmental Disorders, 44(1), 168-179. https://doi.org/10.1007/s10803-013-1862-3

Kasari, C., Gulsrud, A., Freeman, S., Paparella, T., \& Hellemann, G. (2012). Longitudinal follow-up of children with autism receiving targeted interventions on joint attention and play. Journal of the American Academy of Child \& Adolescent Psychiatry, 51(5), 487495. https://doi.org/10.1016/j.jaac.2012.02.019

Kasari, C., Gulsrud, A. C., Wong, C., Kwon, S., \& Locke, J. (2010). Randomized controlled caregiver mediated joint engagement intervention for toddlers with autism. Journal of Autism and Developmental Disorders, 40(9), 1045-1056. https://doi.org/10.1007/s10803-010-0955-5

Kratochwill, T. R., Hitchcock, J., Horner, R. H., Levin, J. R., Odom, S. L., Rindskopf, D. M., \& Shadish, W. R. (2010). Single-case designs technical documentation. Retrieved from http://ies.ed.gov/ncee/wwc/pdf/wwc scd.pdf

Lin, C. E., \& Koegel, R. (2018). Treatment for higher-order restricted repetitive behaviors (H-RRB) in children with autism spectrum disorder. Journal of Autism and Developmental Disorders, 48(11), 3831-3845. https://doi.org/10.1007/s10803-018-3637-3

Little, L. M., Wallisch, A., Pope, E., \& Dunn, W. (2018). Acceptability and cost comparison of a telehealth intervention for families of children with autism. Infants \& Young Children, 31(4), 275-286. https://doi.org/10.1097/IYC.0000000000000126

Maenner, M.J., Shaw, K.A., Baio, J., Washington, A., Patrick, M., DiRienzo, M., ... Dietz, P. (2020). Prevalence of Autism Spectrum Disorder Among Children Aged 8 Years - Autism and Developmental Disabilities Monitoring Network, 11 Sites, United States, 2016. MMWR Surveillance Summaries, 69(4), 1-12. http://dx.doi.org/10.15585/mmwr.ss6904a1

Martinez, M., Thomas, K. C., Williams, C. S., Christian, R., Crais, E., Pretzel, R., \& Hooper, S. R. (2018). Family experiences with the diagnosis of autism spectrum disorder: System barriers and facilitators of efficient diagnosis. Journal of Autism and Developmental Disorders, 48(7), 2368-2378. https://doi.org/10.1007/s10803-018-3493-1

Matson, J. L., \& Goldin, R. L. (2014). What is in the future of assessment for autism spectrum disorders: Short and long term. Research in Autism Spectrum Disorders, 8(3), 209-213. https://doi.org/10.1016/j.rasd.2013.01.007

Matson, J. L., \& Konst, M. J. (2013). What is the evidence for long term effects of early autism interventions? Research in Autism Spectrum Disorders, 7(3), 475-479. https://doi.org/10.1016/j.rasd.2012.11.005

Matson, J. L., \& Rieske, R. D. (2014). Are outcome measures for early intensive treatment of autism improving? Research in Autism Spectrum Disorders, 8(3), 178-185. https://doi.org/10.1016/j.rasd.2013.11.006

McDuffie, A., Oakes, A., Machalicek, W., Ma, M., Bullard, L., Nelson, S., \& Abbeduto, L. (2016). Early language intervention using distance video-teleconferencing: A pilot study of young boys with fragile $\mathrm{X}$ syndrome and their mothers. American Journal of Speech-Language Pathology, 25(1), 46-66. https://doi.org/10.1044/2015 AISLP-14-0137

McIntyre, L. L., \& Zemantic, P. K. (2017). Examining services for young children with autism spectrum disorder: Parent satisfaction and predictors of service utilization. Early Childhood Education Journal, 45(6), 727-734. https://doi.org/10.1007/s10643-016-0821y

McWilliam, R. A., (2010). Routines-based early intervention: Supporting young children and their families. Maryland: Paul H. Brookes. 
Effects of a parent training using telehealth: Equity and access to early intervention...

Mello, M. P., Goldman, S. E., Urbano, R. C., \& Hodapp, R. M. (2016). Services for children with autism spectrum disorder: Comparing rural and non-rural communities. Education and Training in Autism and Developmental Disabilities, 51(4), 355-365. https://www.jstor.org/stable/26173863

Nefdt, N., Koegel, R., Singer, G., \& Gerber, M. (2010). The use of a self-directed learning program to provide introductory training in pivotal response treatment to parents of children with autism. Journal of Positive Behavior Interventions, 12(1), 23-32. https://doi.org/10.1177/1098300709334796

Neely, L., Rispoli, M., Gerow, S., \& Hong, E. R. (2016). Preparing interventionists via telepractice in incidental teaching for children with autism. Journal of Behavioral Education, 25(4), 393-416. https://doi.org/10.1007/s10864-016-9250-7

Olsen, S., Fiechtl, B., \& Rule, S. (2012). An evaluation of virtual home visits in early intervention: Feasibility of “Virtual Intervention". The Volta Review, 112(3), 267-281.

Parker, R. I., Vannest, K. J., \& Davis, J. L. (2011). Effect size in single-case research: A review of nine nonoverlap techniques. Behavior Modification, 35(4), 303-322. https://doi.org/10.1177/0145445511399147

Pickles, A., Le Couteur, A., Leadbitter, K., Salomone, E., Cole-Fletcher, R., Tobin, H., ... Green, J. (2016). Parent-mediated social communication therapy for young children with autism (PACT): Long-term follow-up of a randomised controlled trial. The Lancet, 388(10059), 2501-2509. https://doi.org/10.1016/S0140-6736(16)31229-6

Pierce, K., Gazestani, V. H., Bacon, E., Barnes, C. C., Cha, D., Nalabolu, S., ... Courchesne, E. (2019). Evaluation of the diagnostic stability of the early autism spectrum disorder phenotype in the general population starting at 12 months. JAMA Pediatrics, 173(6), 578-587. https://doi.org/10.1001/jamapediatrics.2019.0624

Reichow, B., Hume, K., Barton, E. E., \& Boyd, B. A. (2018). Early intensive behavioral intervention (EIBI) for young children with autism spectrum disorders (ASD). Cochrane Database of Systematic Reviews. 5,1-56. https://doi.org/ 10.1002/14651858.CD009260.pub3

Rivard, M., Morin, M., Mercier, C., Terroux, A., Mello, C., \& Lépine, A. (2017). Social validity of a training and coaching program for parents of children with autism spectrum disorder on a waiting list for early behavioral intervention. Journal of Child and Family Studies, 26(3), 877-887. https://doi.org/10.1007/s10826-016-0604-5

Roberts, M. Y., \& Kaiser A. P. (2011). The effectiveness of parent-implemented language interventions: A meta-analysis. American Journal of Speech-Language Pathology, 20(3), 180-199. https://doi.org/10.1044/1058-0360(2011/10-0055)

Rogers, S. J., \& Dawson, G. (2010). Early Start Denver Model for young children with autism: Promoting language, learning, and engagement. New York: Guilford Press.

Rogers, S. J., Dawson, G., \& Vismara, L. A. (2012). An early start for your child with autism: Using everyday activities to help kids connect, communicate, and learn. New York: Guilford Press.

Scruggs, T. E., \& Mastropieri, M. A. (1998). Summarizing single-subject research: Issues and applications. Behavior Modification, 22(3), 221-242. https://doi.org/10.1177/01454455980223001

Scruggs, T. E., \& Mastropieri, M. A. (2001). How to summarize single-participant research: Ideas and applications. Exceptionality, 9(4), 227-244. https://doi.org/10.1207/S15327035EX0904_5

Scruggs, T. E., Mastropieri, M. A., \& Casto, G. (1987). The quantitative synthesis of single-subject research: Methodology and validation. Remedial and Special Education, 8(2), 24-33. https://doi.org/10.1177/074193258700800206

Shire, S. Y., Gulsrud, A., \& Kasari, C. (2016). Increasing responsive parent-child interactions and joint engagement: Comparing the influence of parent-mediated intervention and parent psychoeducation. Journal of Autism and Developmental Disorders, 46(5), 1737-1747. https://doi.org/10.1007/s10803-016-2702-z

Siller, M., \& Morgan, L. (2018). Systematic review of research evaluating parent-mediated interventions for young children with autism: Years 2013 to 2015. In M. Siller \& L. Morgan (Eds.) Handbook of parent-implemented interventions for very young children with autism (1 ${ }^{\text {st }}$ ed., pp. 1-21). Springer. https://doi.org/10.1007/978-3-319-90994-3 1

Simacek, J., Dimian, A., \& McComas, J. (2017). Communication intervention for young children with severe neurodevelopmental disabilities via telehealth. Journal of Autism and Developmental Disorders, 47(3), 744-767. https://doi.org/10.1007/s10803-016$\underline{3006-\mathrm{z}}$

Smith-Young, J., Chafe, R., \& Audas, R. (2020). “Managing the wait”: Parents' experiences in accessing diagnostic and treatment services for children and adolescents diagnosed with autism spectrum disorder. Health Services Insights, 13, 1-10. https://doi.org/10.1177/1178632920902141

Suess, A. N., Wacker, D. P., Schwartz, J. E., Lustig, N., \& Detrick, J. (2016). Preliminary evidence on the use of telehealth in an outpatient behavior clinic. Journal of Applied Behavior Analysis, 49(3), 686-692. https://doi.org/10.1002/jaba.305

Vismara, L. A., McCormick, C. E., Wagner, A. L., Monlux, K., Nadhan, A., \& Young, G. S. (2018). Telehealth parent training in the Early Start Denver Model: Results from a randomized controlled study. Focus on Autism and Other Developmental Disabilities, 33(2), 67-79. https://doi.org/10.1177/1088357616651064 


\section{Deborah L. ROOKS-ELLIS et al.}

Wacker, D. P., Lee, J. F., Dalmau, Y. C. P., Kopelman, T. G., Lindgren, S. D., Kuhle, J., ... Waldron, D. B. (2013). Conducting functional communication training via telehealth to reduce the problem behavior of young children with autism. Journal of developmental and physical disabilities, 25(1), 35-48. https://doi.org/10.1007/s10882-012-9314-0

Wainer, A. L., \& Ingersoll, B. R. (2015). Increasing access to an ASD imitation intervention via a telehealth parent training program. Journal of Autism and Developmental Disorders, 45(12), 3877-3890. https://doi.org/10.1007/s10803-014-2186-7

Wallace, K. S., \& Rogers, S. J. (2010). Intervening in infancy: Implications for autism spectrum disorders. Journal of Child Psychology and Psychiatry, 51(12), 1300-1320. https://doi.org/10.1111/j.1469-7610.2010.02308.x

Webb, S., Jones, E., Kelly, J. \& Dawson, G. (2014). The motivation for very early intervention for infants at high risk for autism spectrum disorders. International Journal of Speech-Language Pathology, 16(1), 36-42. https://doi.org/10.3109/17549507.2013.861018

What Works Clearinghouse. (2020). Procedures and standards handbook (Version 4.1). Washington, DC: U.S. Department of Education, Institute of Education Sciences, National Center for Education Evaluation and Regional Assistance. Retrieved from https://ies.ed.gov/ncee/wwc/handbooks

Wong, C., Odom, S. L., Hume, K. A., Cox, A. W., Fettig, A., Kucharczyk, S., ... Schultz, T. R. (2015). Evidence-based practices for children, youth, and young adults with autism spectrum disorder: A comprehensive review. Journal of Autism and Developmental Disorders, 45(7), 1951-66. https://doi.org/10.1007/s10803-014-2351-z

Zwaigenbaum, L., Bauman, M. L., Choueiri, R., Kasari, C., Carter, A., Granpeesheh, D., ... Natowicz, M. R. (2015). Early intervention for children with autism spectrum disorder under 3 years of age: Recommendations for practice and research. Pediatrics, 136(Supplement 1), 60-S81. https://doi.org/10.1542/peds.2014-3667E 
Appendix A

Figure 1. Parent Fidelity of Implementation of P-ESDM

Baseline

Intervention

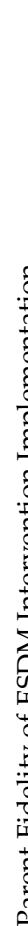

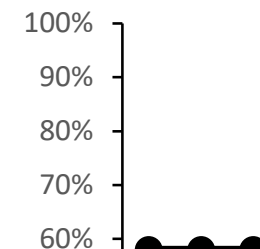

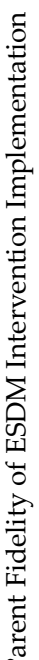

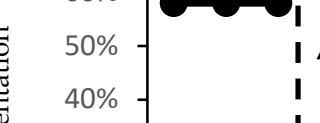

$\begin{array}{ll}50 \%-1 & \text { I } \\ 40 \%-1 & \text { I } \\ 30 \%-1 & \text { I }\end{array}$

$20 \%-1$
$10 \%-1$
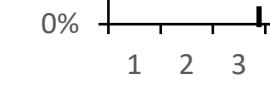

$100 \%$

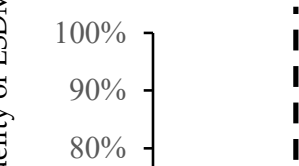

$90 \%$
$80 \%$

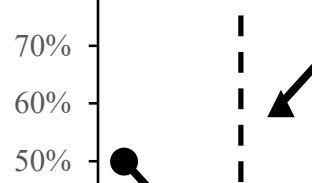

40\%

$30 \%$

$20 \%$

$10 \%$

$0 \%$

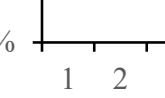

Maintenance

Generalization

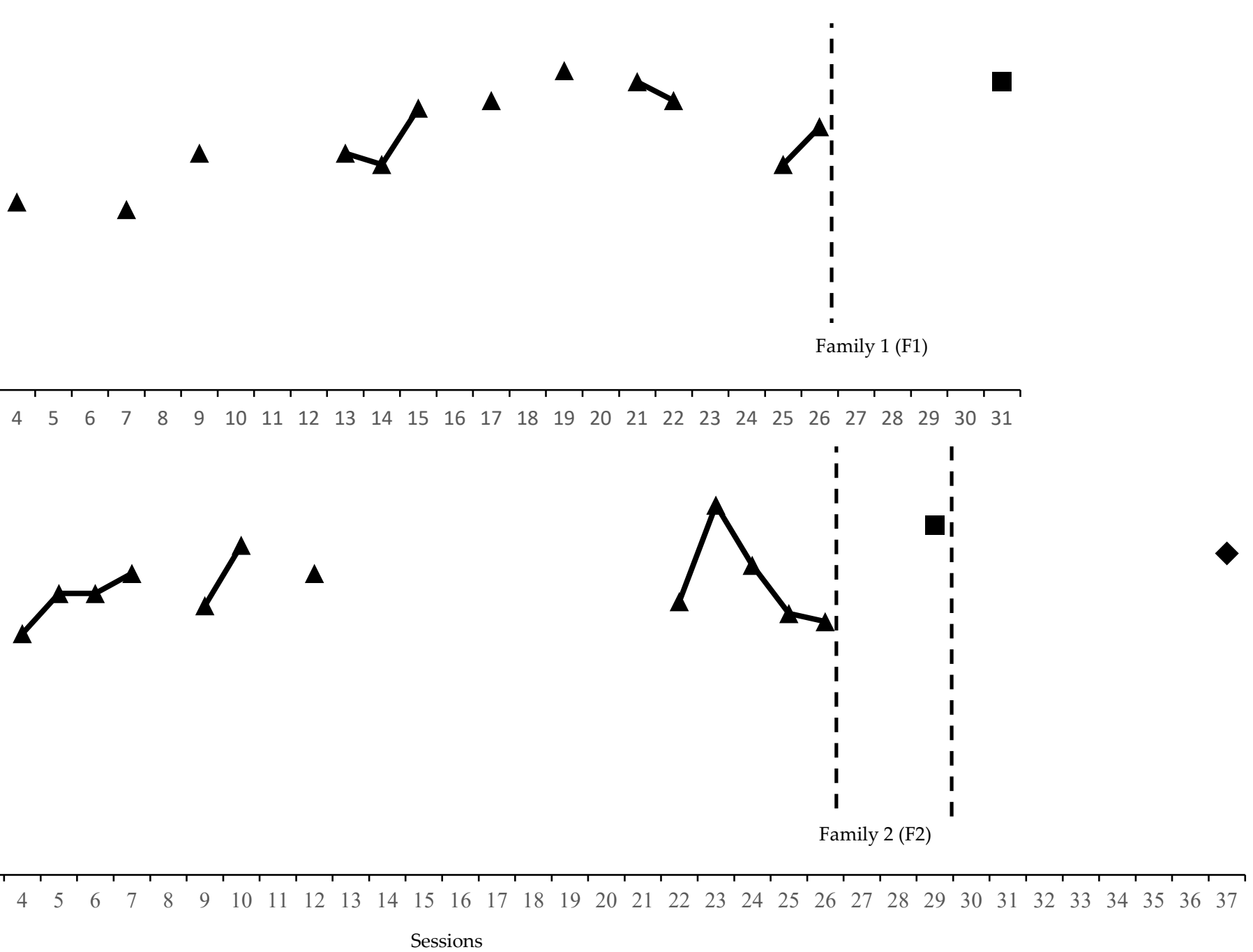


Deborah L. ROOKS-ELLIS et al.

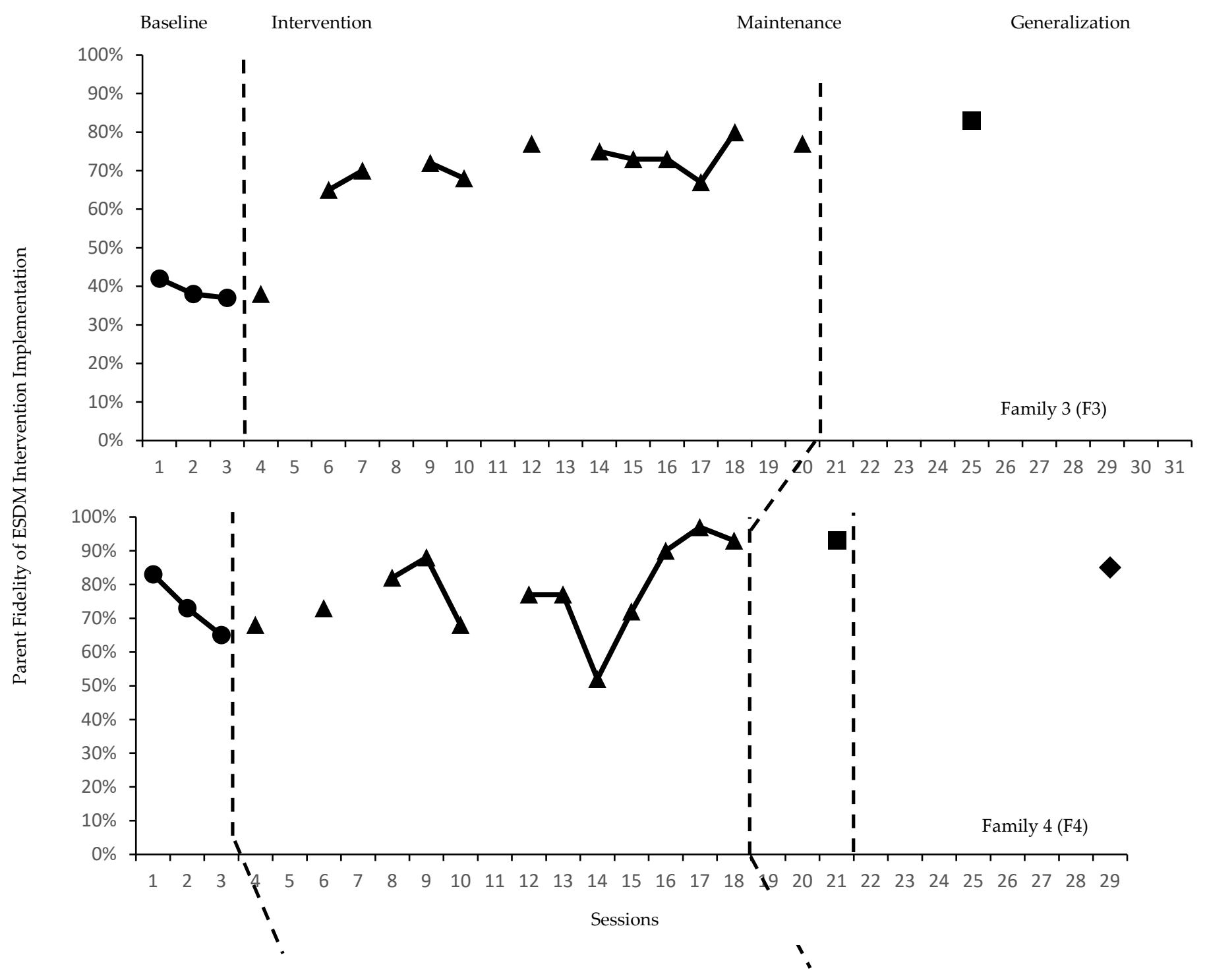


Baseline Intervention

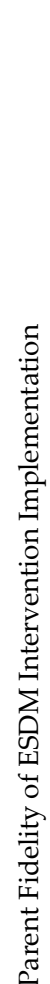

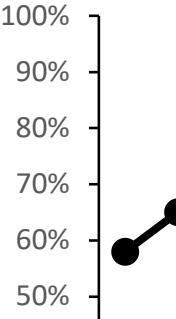

i

$0 \%$

12

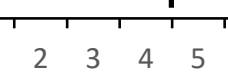

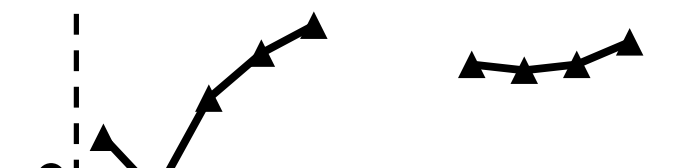

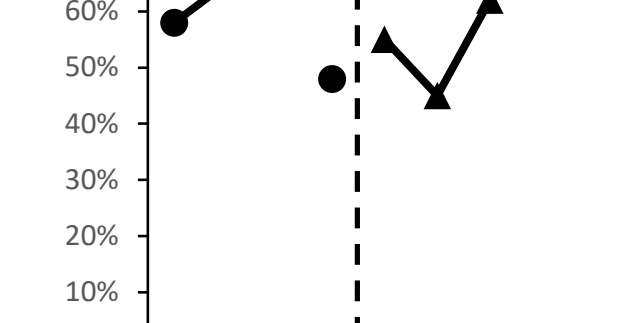

$\begin{array}{lllll}7 & 8 & 9 & 1\end{array}$
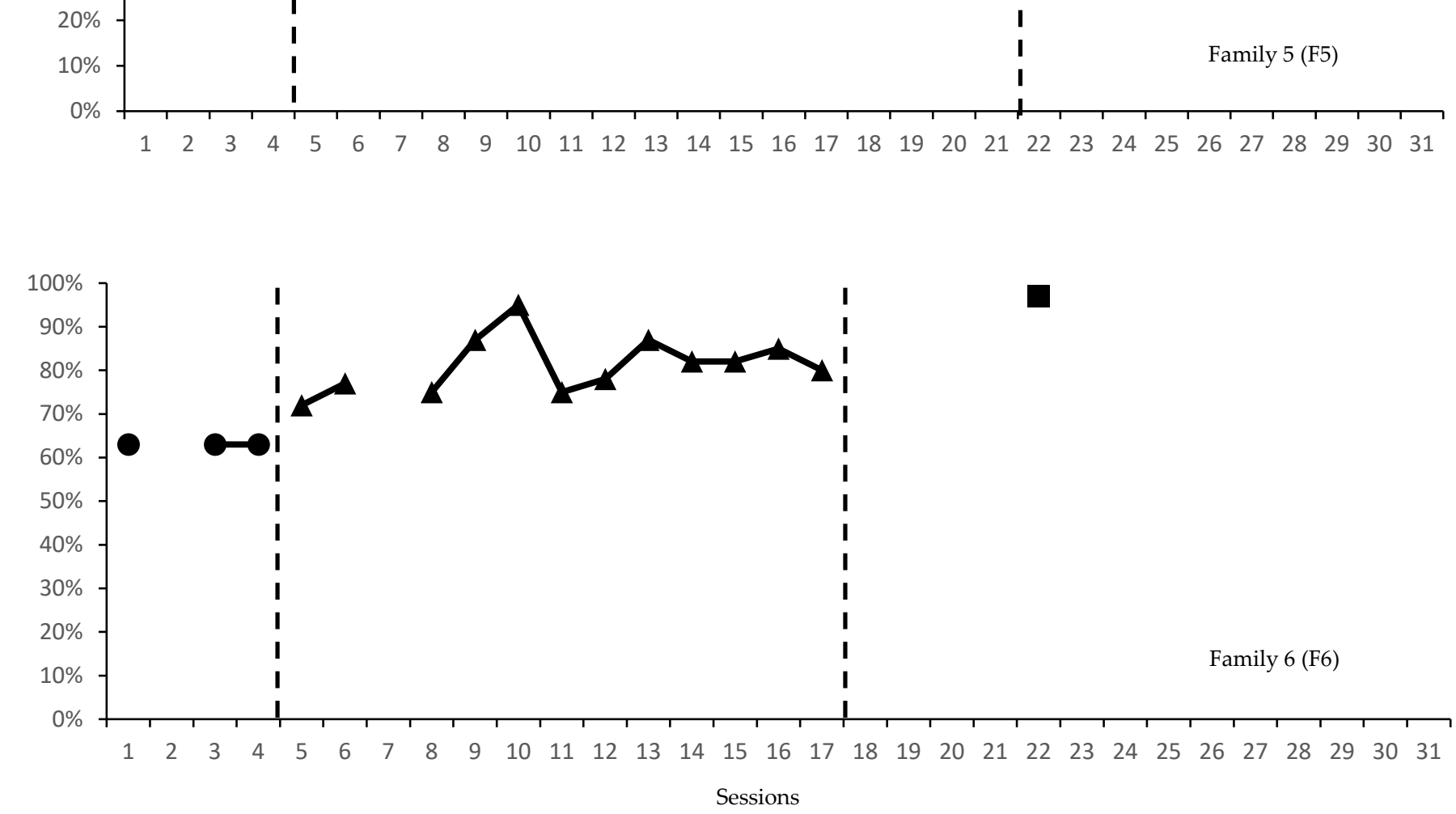
Deborah L. ROOKS-ELLIS et al.

Baseline Intervention Maintenance Generalization

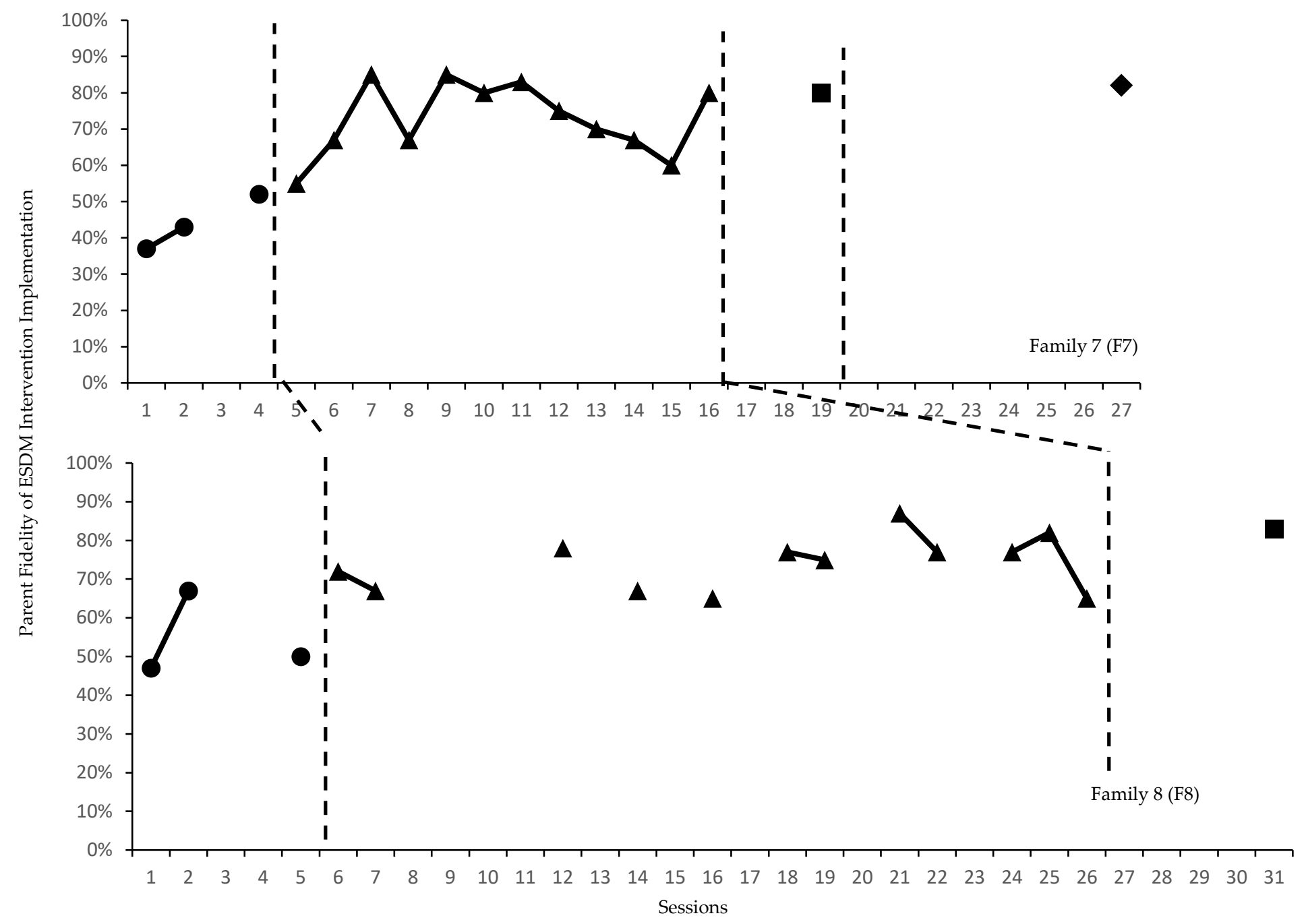


Baseline Intervention

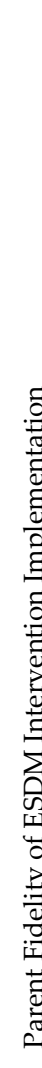

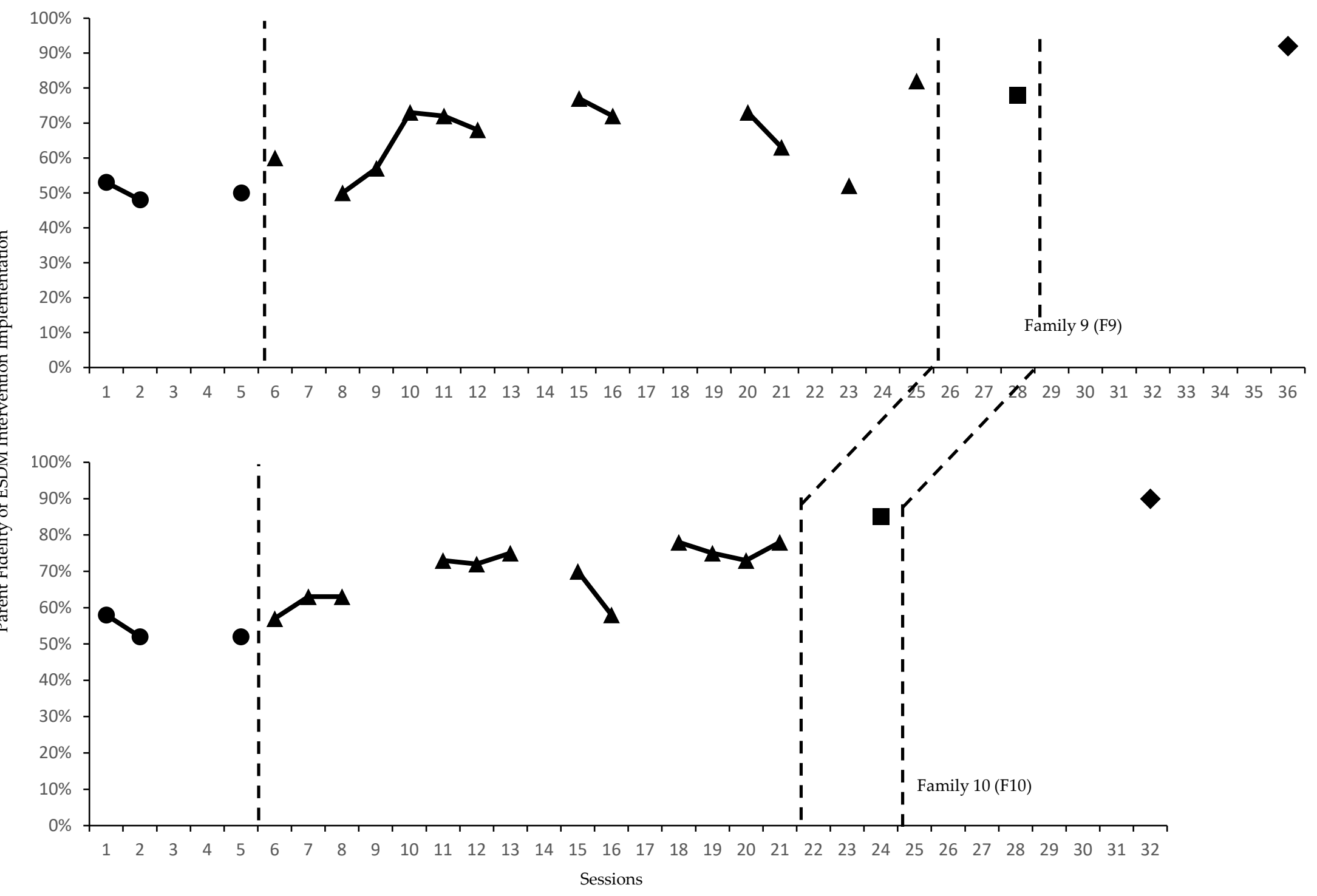


Deborah L. ROOKS-ELLIS et al.

\section{Appendix B}

Items and Difference Between Means of the Autism Impact Measure

\begin{tabular}{|c|c|c|c|c|c|c|c|}
\hline \multirow[t]{2}{*}{ Item \# } & \multirow[t]{2}{*}{ Item } & \multicolumn{2}{|c|}{ Pre-Intervention } & \multicolumn{2}{|c|}{ Post-Intervention } & \multirow[b]{2}{*}{$M$ difference } & \multirow[b]{2}{*}{$p$} \\
\hline & & $M$ & SD & $M$ & $\mathrm{SD}$ & & \\
\hline \multicolumn{8}{|c|}{ Frequency Items } \\
\hline 1 & $\begin{array}{l}\text { Shown fascination with parts of objects } \\
\text { rather than the whole toy }\end{array}$ & 3.10 & 1.10 & 3.20 & 1.40 & 0.10 & .276 \\
\hline 2 & $\begin{array}{l}\text { Been fascinated with looking at, feeling, } \\
\text { touching, and licking certain objects }\end{array}$ & 3.10 & 1.66 & 2.70 & 1.57 & 0.40 & .194 \\
\hline 3 & Lined things up & 2.00 & 1.70 & 2.60 & 1.65 & 0.60 & .273 \\
\hline 4 & $\begin{array}{l}\text { Responded oddly or inappropriately to } \\
\text { others }\end{array}$ & 2.00 & 1.33 & 1.70 & 1.06 & 0.30 & .453 \\
\hline 5 & $\begin{array}{l}\text { Used someone else's hand to point, touch } \\
\text { or perform a task }\end{array}$ & 2.60 & 1.65 & 1.70 & .823 & 0.90 & $* .041$ \\
\hline 6 & $\begin{array}{l}\text { Had speech problems or been hard to } \\
\text { understand }\end{array}$ & 4.00 & 1.41 & 2.75 & 1.26 & 1.25 & .083 \\
\hline 7 & $\begin{array}{l}\text { Had certain rituals or routines that have to } \\
\text { be followed }\end{array}$ & 2.20 & 1.48 & 1.70 & 1.06 & 0.50 & .160 \\
\hline 8 & $\begin{array}{l}\text { Used odd or unusual pitch, volume or } \\
\text { tone when talking }\end{array}$ & 1.70 & 1.16 & 2.10 & 1.37 & 0.40 & .496 \\
\hline 9 & $\begin{array}{l}\text { Withdrawn from playing with children of } \\
\text { the same age }\end{array}$ & 2.60 & 1.67 & 2.67 & 1.51 & 0.07 & .854 \\
\hline 10 & Repeated actions over and over & 2.40 & 1.26 & 2.10 & 1.29 & .30 & .317 \\
\hline 11 & Had a strong interest in collecting things & 1.80 & 1.46 & 1.10 & .316 & 0.70 & .102 \\
\hline 12 & $\begin{array}{l}\text { Shown repetitive hand or finger } \\
\text { movements }\end{array}$ & 2.90 & 1.37 & 2.00 & 1.33 & 0.90 & .121 \\
\hline 13 & $\begin{array}{l}\text { Shown strong attachments to unusual } \\
\text { toys or objects }\end{array}$ & 1.00 & .000 & 1.10 & .316 & 0.10 & .317 \\
\hline 14 & $\begin{array}{l}\text { Experienced problems with repetitive } \\
\text { behaviors or restricted interests }\end{array}$ & 1.80 & 1.14 & 1.60 & 1.07 & 0.20 & .414 \\
\hline 15 & $\begin{array}{l}\text { Avoided certain sounds, textures or } \\
\text { smells to an unusual extent }\end{array}$ & 2.00 & 1.49 & 2.10 & 1.60 & 0.10 & .891 \\
\hline 16 & Appeared aloof, distant or detached & 2.60 & 1.07 & 1.90 & .876 & .70 & .068 \\
\hline 17 & $\begin{array}{l}\text { Had repetitive movements with his/her } \\
\text { whole body }\end{array}$ & 2.50 & 1.58 & 1.60 & .843 & .90 & .059 \\
\hline 18 & $\begin{array}{l}\text { Experienced problems in communicating } \\
\text { with others (verbally and/or nonverbally) }\end{array}$ & 4.30 & .949 & 2.80 & .789 & 1.50 & *.004 \\
\hline 19 & $\begin{array}{l}\text { Approached others in odd or in an } \\
\text { inappropriate way }\end{array}$ & 1.60 & 1.07 & 1.30 & .675 & 0.30 & .257 \\
\hline 20 & $\begin{array}{l}\text { Shown a preoccupation with one subject } \\
\text { or area of interest }\end{array}$ & 1.60 & 1.07 & 1.30 & .675 & 0.30 & .450 \\
\hline 21 & $\begin{array}{l}\text { Had difficulty showing or accepting } \\
\text { affection }\end{array}$ & 1.40 & .699 & 1.20 & .422 & 0.20 & .414 \\
\hline 22 & Resisted changes in routines & 2.50 & 1.58 & 1.40 & .966 & 1.10 & ${ }^{*} .014$ \\
\hline 23 & Had problems with pronouns & 3.66 & 2.31 & 3.00 & 1.63 & .66 & 1.00 \\
\hline 24 & Used repetitive or odd phrases & 1.50 & 1.22 & 1.56 & 1.13 & .06 & 1.00 \\
\hline 25 & Echoed words or phrases & 1.86 & 1.36 & 2.10 & 1.66 & .24 & .705 \\
\hline 26 & $\begin{array}{l}\text { Experienced problems in social } \\
\text { interactions }\end{array}$ & 3.10 & 1.37 & 2.50 & 1.18 & .60 & *.034 \\
\hline 27 & Used a private or made up language & 2.40 & 1.90 & 1.80 & 1.03 & .60 & .180 \\
\hline$\wedge 28$ & Played with same age friends & 2.33 & 1.51 & 2.60 & 1.67 & .27 & 1.00 \\
\hline$\wedge 29$ & Held back and forth conversations & 3.00 & .817 & 3.67 & .577 & .67 & .157 \\
\hline$\wedge 30$ & $\begin{array}{l}\text { Shared his enjoyment or excitement with } \\
\text { others }\end{array}$ & 1.60 & 1.07 & 2.50 & 1.43 & .90 & ${ }^{*} .034$ \\
\hline$\wedge 31$ & $\begin{array}{l}\text { Played cooperatively with groups of } \\
\text { children }\end{array}$ & 2.80 & 2.05 & 3.75 & 1.50 & .95 & 1.80 \\
\hline$\wedge 32$ & $\begin{array}{l}\text { Responded positively to other children's } \\
\text { approaches }\end{array}$ & 2.11 & 1.69 & 2.20 & 1.56 & .09 & .480 \\
\hline
\end{tabular}


Effects of a parent training using telehealth: Equity and access to early intervention...

\begin{tabular}{|c|c|c|c|c|c|c|c|}
\hline$\wedge 33$ & $\begin{array}{l}\text { Used a social smile to greet people or } \\
\text { respond to them }\end{array}$ & 1.60 & 1.07 & 2.70 & 1.57 & 1.10 & *.026 \\
\hline$\wedge 34$ & Used gestures to communicate & 2.30 & 1.16 & 3.80 & 1.23 & 1.50 & *.006 \\
\hline$\wedge 35$ & Comforted others when they were upset & 3.60 & 1.43 & 4.67 & .707 & 1.07 & .058 \\
\hline$\wedge 36$ & $\begin{array}{l}\text { Seemed interested in other children his } \\
\text { age }\end{array}$ & 2.33 & 1.58 & 3.20 & 1.75 & .87 & ${ }^{*} .008$ \\
\hline$\wedge 37$ & Played using his imagination & 2.80 & 1.55 & 3.20 & 1.48 & .40 & .391 \\
\hline$\wedge 38$ & Used social chit chat & 3.50 & 1.73 & 5.00 & .000 & 1.50 & .317 \\
\hline$\wedge 39$ & $\begin{array}{l}\text { Used a number of different facial } \\
\text { expressions }\end{array}$ & 2.10 & 1.45 & 3.00 & 1.49 & .90 & .084 \\
\hline$\wedge 40$ & $\begin{array}{l}\text { Brought things to others just to share his } \\
\text { interest }\end{array}$ & 2.70 & 1.70 & 3.40 & 1.26 & .70 & .229 \\
\hline$\wedge 41$ & Made eye contact with others & 2.00 & .942 & 2.50 & 1.08 & .50 & .276 \\
\hline \multicolumn{8}{|c|}{ Impact Items } \\
\hline 1 & $\begin{array}{l}\text { Fascination with parts of objects rather } \\
\text { than the whole toy }\end{array}$ & 2.10 & .876 & 1.90 & .994 & .20 & .516 \\
\hline 2 & $\begin{array}{l}\text { Fascination with looking at, feeling, } \\
\text { touching, and licking objects }\end{array}$ & 2.40 & 1.35 & 1.60 & .843 & .08 & .071 \\
\hline 3 & Lined things up & 1.40 & .966 & 1.20 & .421 & .20 & .317 \\
\hline 4 & Responded oddly to others & 1.80 & 1.48 & 1.50 & 1.08 & .30 & .461 \\
\hline 5 & $\begin{array}{l}\text { Used someone else's hand to point, touch } \\
\text { or perform a task }\end{array}$ & 1.80 & 1.03 & 1.40 & .843 & .40 & .157 \\
\hline 6 & $\begin{array}{l}\text { Had speech problems or been hard to } \\
\text { understand }\end{array}$ & 3.50 & 1.73 & 2.75 & 1.26 & .75 & .317 \\
\hline 7 & $\begin{array}{l}\text { Had certain rituals or routines that have to } \\
\text { be followed }\end{array}$ & 2.00 & 1.41 & 1.40 & .843 & .60 & ${ }^{*} .034$ \\
\hline 8 & $\begin{array}{l}\text { Used odd or unusual pitch, volume or } \\
\text { tone when talking }\end{array}$ & 1.80 & 1.32 & 1.40 & .699 & .40 & .357 \\
\hline 9 & $\begin{array}{l}\text { Withdrawn from playing with children of } \\
\text { the same age }\end{array}$ & 2.40 & 1.95 & 2.50 & 1.76 & .10 & .317 \\
\hline 10 & Repeated actions over and over & 2.10 & .994 & 1.50 & .850 & .60 & .063 \\
\hline 11 & Had a strong interest in collecting things & 1.50 & 1.08 & 1.00 & .000 & .50 & .180 \\
\hline 12 & $\begin{array}{l}\text { Shown repetitive hand or finger } \\
\text { movements }\end{array}$ & 1.30 & .949 & 1.00 & .000 & .30 & .317 \\
\hline 13 & $\begin{array}{l}\text { Shown strong attachments to unusual } \\
\text { toys or objects }\end{array}$ & 1.00 & .000 & 1.10 & .316 & .10 & .317 \\
\hline 14 & $\begin{array}{l}\text { Experienced problems with repetitive or } \\
\text { restricted behaviors }\end{array}$ & 1.60 & .843 & 1.40 & .699 & .20 & .157 \\
\hline 15 & $\begin{array}{l}\text { Avoided certain sounds, textures or } \\
\text { smells }\end{array}$ & 1.80 & 1.32 & 2.00 & 1.63 & .20 & .655 \\
\hline 16 & Appeared aloof, distant or detached & 2.30 & 1.16 & 1.60 & .843 & .70 & .066 \\
\hline 17 & $\begin{array}{l}\text { Had repetitive movements with his whole } \\
\text { body }\end{array}$ & 1.70 & 1.06 & 1.10 & .316 & .60 & .109 \\
\hline 18 & $\begin{array}{l}\text { Experienced problems in communicating } \\
\text { with others }\end{array}$ & 4.00 & 1.25 & 2.70 & .823 & 2.30 & ${ }^{*} .010$ \\
\hline 19 & $\begin{array}{l}\text { Approached others in odd or in an } \\
\text { inappropriate way }\end{array}$ & 1.60 & 1.07 & 1.20 & .632 & .40 & .102 \\
\hline 20 & $\begin{array}{l}\text { Shown a preoccupation with one subject } \\
\text { or area of interest }\end{array}$ & 1.40 & .699 & 1.20 & .421 & .20 & .414 \\
\hline 21 & $\begin{array}{l}\text { Had difficulty showing or accepting } \\
\text { affection }\end{array}$ & 1.2 & .422 & 1.00 & .000 & .20 & .157 \\
\hline 22 & Resisted changes in routines & 2.40 & 1.43 & 1.50 & 1.08 & .90 & *.024 \\
\hline 23 & Had problems with pronouns & 1.33 & .577 & 1.75 & 1.50 & .42 & .317 \\
\hline 24 & Used repetitive or odd phrases & 1.00 & .000 & 1.22 & .441 & .22 & .317 \\
\hline 25 & Echoed words or phrases & 1.25 & .463 & 1.20 & .632 & .05 & 1.0 \\
\hline 26 & $\begin{array}{l}\text { Experienced problems in social } \\
\text { interactions }\end{array}$ & 2.70 & 1.49 & 2.60 & 1.07 & .10 & .792 \\
\hline 27 & Used a private or made up language & 1.70 & 1.16 & 1.11 & .333 & .59 & .276 \\
\hline
\end{tabular}


Deborah L. ROOKS-ELLIS et al.

\begin{tabular}{|c|c|c|c|c|c|c|c|}
\hline$\wedge 28$ & Played with same age friends & 1.28 & .756 & 2.00 & 1.73 & .72 & .655 \\
\hline$\wedge 29$ & Held back and forth conversations & 1.50 & 1.00 & 2.00 & 1.00 & .50 & .317 \\
\hline$\wedge 30$ & $\begin{array}{l}\text { Shared his enjoyment or excitement with } \\
\text { others }\end{array}$ & 1.44 & .881 & 1.50 & 1.08 & .06 & .655 \\
\hline$\wedge 31$ & $\begin{array}{l}\text { Played cooperatively with groups of } \\
\text { children }\end{array}$ & 2.20 & 1.79 & 2.75 & 2.06 & .55 & 1.0 \\
\hline$\wedge 32$ & $\begin{array}{l}\text { Responded positively to other children's } \\
\text { approaches }\end{array}$ & 1.70 & 1.49 & 2.40 & 1.71 & .70 & .109 \\
\hline$\wedge 33$ & $\begin{array}{l}\text { Used a social smile to greet people or } \\
\text { respond to them }\end{array}$ & 1.00 & .000 & 1.70 & 1.34 & .70 & .109 \\
\hline$\wedge 34$ & Used gestures to communicate & 2.00 & 1.33 & 3.20 & 1.81 & 1.20 & .092 \\
\hline$\wedge 35$ & Comforted others when they were upset & 1.00 & .000 & 1.20 & .422 & .20 & .157 \\
\hline$\wedge 36$ & $\begin{array}{l}\text { Seemed interested in other children his } \\
\text { age }\end{array}$ & 1.90 & 1.20 & 2.11 & 1.54 & .21 & .461 \\
\hline$\wedge 37$ & Played using his imagination & 1.10 & .316 & 1.80 & 1.40 & .70 & .141 \\
\hline$\wedge 38$ & Used social chit chat & 1.00 & .000 & 2.33 & 1.53 & 1.33 & .180 \\
\hline$\wedge 39$ & $\begin{array}{l}\text { Used a number of different facial } \\
\text { expressions }\end{array}$ & 1.10 & .316 & 2.00 & 1.15 & .90 & .059 \\
\hline$\wedge 40$ & $\begin{array}{l}\text { Brought things to others just to share his } \\
\text { interest }\end{array}$ & 1.80 & 1.32 & 1.50 & .850 & .30 & .496 \\
\hline$\wedge 41$ & Made eye contact with others & 1.60 & .966 & 2.70 & 1.25 & 1.10 & *.026 \\
\hline
\end{tabular}

